\title{
Los Atributos De Sexo Y Género en El Arte Rupestre en Seis Condados De Utah
}

\author{
Michael Cartmill ${ }^{1}$, Samantha Shipley ${ }^{2}$ b \\ ${ }^{1}$ Dixie State University, ${ }^{2}$ Weber State University \\ Keywords: papel de género, utah, arte rupestre \\ https://doi.org/10.36898/001c. 25275
}

Curiosity: Interdisciplinary Journal of Research and Innovation

Este estudio evalúa las maneras en que se interpretan el género y el papel de las mujeres en el arte rupestre de Utah. Se evaluaron seis condados de Utah-Box Elder, Carbon, Juab, Millard, Tooele y Utah. Junto con un repaso de la literatura pertinente, este estudio empleó formas de sitios de arte rupestre para analizar cualquier indicio de atributos de sexo o género. Las imágenes y dibujos resultaron ser lo más beneficioso para explicar cómo diferentes símbolos podrían indicar atributos de sexo y género encontrados entre el arte rupestre. Aunque parte del arte rupestre es más fácil de descifrar, la mayoría se presta a la interpretación y requiere un conocimiento amplio de la cultura junto con un análisis etnográfico. Comprender cómo el género se representa en el arte rupestre puede ilustrar cómo las relaciones de género funcionaban dentro de una sociedad prehistórica. Esta investigación puede ayudar a "desgenerizar" la arqueología y proveer un punto de vista diferente para utilizar al estudiar el arte rupestre. También puede apoyar con desarmar las perspectivas etnocéntricas dentro del campo y contribuir a los estudios de sexo y género no arqueológicos dentro de diferentes contextos culturales.

\section{Introducción}

En Utah, el arte rupestre surgió hace miles de años por grupos de nativo americanos que consideraban esta región su hogar, y mucho antes de la llegada de los europeos y los euroamericanos. El arte rupestre en Utah se creó por los paleoindios, los anasazis, los fremont, los grupos de habla númica, y tribus históricamente conocidas tales como los ute, los navajos (aunque mucho de eso se debate debido a la dificultad de datar el arte rupestre) (Schaafsma, 1971). Patrones y características compartidas pueden identificar el estilo distinto de cada grupo (Schaafsma, 1971). Estilos comunes en Utah incluyen el Estilo Barrier Canyon, el Estilo 5 Glen Canyon, el Estilo Uncompahgre, el Estilo San Juan Basketmaker, Estilos Pueblo I y Pueblo II-III, Estilo Abajo-La Sal y el Estilo San Rafael (Schaafsma, 1971; Scotter \& Bowen, 2019). Este trabajo se enfocará en los condados de Tooele, Utah, Juab, Carbon, Box Elder y Millard, todos ubicados en la región norteña de Utah.

\footnotetext{
a Dr. Cartmill is the Director of Global Education at Dixie State University and an Associate Professor of Spanish. Dr. Michael Cartmill is the translator of this article.

b Samantha C. Shipley graduated from Weber State University in December 2019 receiving a Bachelor's of Science degree with a major in Anthropology and a minor in Geography. During the summer of 2019, she had the opportunity to intern with the Utah Division of State History under the direction of Dr. Christopher Merritt to study sex and gender attributions among rock art in Utah. In February 2020 she presented her research at the Utah Conference on Undergraduate Research. Currently, she is in the process of applying to graduate programs in hopes of studying biological anthropology. Samantha thoroughly enjoys all branches of anthropology, but has found biological anthropology to be the most compelling and something she would like to pursue as a career. Samantha Shipley is the original author of this article.
} 


\section{El lugar del arte rupestre en la historia humana}

Sabo \& Sabo (2019) definen el arte rupestre como "imágenes representadas en superficies de roca natural inamovible, tales como la faz de peñascos, muros de cuevas y rocas grandes." Incluye dos tipos comunes (petroglifos y pictografías). Los petroglifos se crean al quitar partes de la superficie de la roca, que se hace más comúnmente al picar o rayar la roca. Las pictografías se crean al pintar en la superficie de la roca con minerales y/o material vegetal (Cole, 2009). Aunque el arte rupestre puede ser ambiguo, su valor es incalculable a la hora de comprender a los seres humanos prehistóricos. El arte rupestre es más que rayas y salpicaduras de pintura en las rocas; es una manera de socializarse y ofrece un vistazo a la vida prehistórica utilizando patrones, distribución y técnicas aplicadas. También muestra los roles de género, costumbres rituales, registros y una cantidad de otras características exclusivamente humanas (HaysGilpin, 2004a).

Con la ayuda del arte rupestre, podemos comprender mejor el comportamiento humano de culturas antiguas de todo el mundo. Desde un punto de vista evolutivo, su aparición nos ha ayudado a limitar el período de tiempo cuando la inteligencia humana empezó a dispararse en comparación con otros mamíferos (Bednarik, 2015). El arte rupestre puede proveer evidencia de cuándo los seres humanos desarrollaron sistemas sociales más complejos y la habilidad de entender el significado simbólico. Se cree que los seres humanos crearon el arte rupestre más antiguo conocido hace unos dos a trescientos mil años en la India (Bednarik, 2015). La creación simbólica refleja la divergencia del Homo sapiens de otras especies de mamíferos. Lo cual muestra un salto importante en las habilidades cognitivas de los seres humanos y nos ayuda a comprender la evolución de nuestra especie.

Las investigaciones del arte rupestre en las sociedades contemporáneas nos han mostrado cómo pueblos anteriores vivieron, cómo obtuvieron alimentos, sus costumbres de iniciación social y mucho más (Bednarik, 2015; Brady, 2016; Sabo \& Sabo, 2019). El arte rupestre también expresa la ideología y la identidad de grupos, patrones de migración, uso del paisaje, espacio sagrado o profano y otros universales humanos que continúan hoy en día (McMurtrey, 2015). Los modelos que usamos para interpretar el arte rupestre también pueden ser útiles para comprender ideologías y dinámicas contemporáneas (ej., Rogers, 2007, p. 87). El modelo chamánico-neuropsicológico, originalmente desarrollado por David Lewis-Williams, señala al chamanismo como la razón principal para la creación del arte rupestre. David Whitley ha aplicado este modelo a mucho del arte rupestre encontrado en la región de la Gran Cuenca (Whitley, 1998). El problema con este modelo es que no incluye a las mujeres porque las mujeres no eran chamanes en las culturas estudiadas (Rogers, 2007, p. 92-94).

Mientras parte del arte rupestre se puede datar y explicar por medio de etnografía o cultura material, el arte rupestre en la mayoría de los contextos arqueológicos permanece enigmático. Por ejemplo, estudios etnográficos e historias de los descendientes de los artistas identifican el arte rupestre san en África subsahariana (Solomon, 1997). Sin embargo, el arte rupestre encontrado 
en Noruega occidental en un sitio llamado Vingen ha sido particularmente desconcertante al identificar tanto el quién como el qué de su creación. El arte rupestre sin ninguna característica de período distintiva tal como otros artefactos o etnografías puede ser más desafiante para ubicar en un período de tiempo. Intentos tempranos de la datación del arte rupestre de Vingen lo colocaron en un lugar entre "el Neolítico inicial hasta el final del Neolítico medio, con un origen posible en el Mesolítico final” (Lødøen, 2003). Se propuso esta estimación basado en el material arqueológico y la relación a orillas cercanas.

La etnografía es esencial para los arqueólogos al interpretar sus hallazgos, incluyendo el arte rupestre. Liam A. Brady expresa la importancia de la etnografía "para desarrollar una mejor comprensión de cómo la significancia y el valor se atribuyen a sitios y motivos" (Brady, 2016). Podemos interpretar un petroglifo de una figura antropomórfica con una línea con una punta aguda al extremo de lo que parece ser un brazo de muchas maneras. Si sabemos que el arte se hizo por los antepasados de una sociedad que todavía obtiene sus alimentos por medio de prácticas de cazador-recolector tal como sus antepasados, podemos concluir con más confianza que la línea con la punta aguda es una lanza. En el ejemplo del arte rupestre san, podemos hacer una referencia cruzada de sus historias, mitos y costumbres culturales actuales para entender sus costumbres culturales y arte rupestre. Usamos etnografías para comprender otros aspectos de culturas antiguas también. Muchos ritos, ceremonias, oraciones religiosas, etc. pasan de generación en generación y permanecen relativamente inalterados.

Con o sin conexiones etnográficas, los investigadores tienen que usar métodos científicos y arqueológicos para proveer métodos de datación más formales. La cronología del arte rupestre ha sido uno de los aspectos más fundamentales, aunque desafiantes, de clasificación, e interpretación (Liritzis, 2010; Lødøen, 2003). Estos son métodos relativos o absolutos de datación. Los métodos relativos de datación se basan mayormente en observaciones, mientras los métodos absolutos consisten en realizar pruebas científicas con materiales en el sitio. Distinguir entre un petroglifo y una pictografía determina qué método usar. Los métodos relativos de datación pueden ser un poco subjetivos debido al hecho de que dependen de la observación del investigador (esto incluye cualquier parcialidad que pueden tener). James D. Keyser (2001) describe ocho maneras para datar el arte rupestre de manera relativa incluyendo la asociación con depósitos arqueológicos datados, la asociación con arte portable (móvil) fechado, materia de estudio fechable (caballos en el Nuevo Mundo por ejemplo), la superposición de diseños, el barniz y el desgaste de las rocas, el acceso físico a las imágenes, el conocimiento etnográfico y materiales usados en la producción del arte. Por ejemplo, Trond Lødøen (2003) describe cómo el lugar del arte y factores geológicos, equivalente a la orilla o un área, pueden darnos una idea de cuándo se creó el arte, pero no siempre es lo bastante preciso o suficiente para llegar a más análisis. Muchos arqueólogos clasifican y asocian diferentes 'estilos' de arte rupestre con diferentes grupos basándose 
en conocimiento etnográfico (Rosenfeld \& Smith, 2002). Esto deja espacio para parcialidades y suposiciones falsas lo cual quita el método científico de la investigación.

Los métodos absolutos de datación, por otro lado, son mucho más precisos y nos pueden proveer de un período de tiempo más definitivo, en vez de una estimación. La mayoría de los métodos absolutos de datación no se pueden aplicar a los petroglifos porque hay poco o ningún material orgánico que extraer. No obstante, en algunos casos, es posible si se ha formado material mineral encima del grabado (Geib \& Fairley, 1992). Fechar con radiocarbono es uno de los primeros métodos absolutos de datación aplicado al arte rupestre. La primera fecha directa de radiocarbono del arte rupestre se publicó en 1987 por Hedges et al. (1987) y desde entonces se ha usado para datar muchos sitios arqueológicos. Uno puede fechar usando radiocarbono con pigmento de una pictografía (Bednarik, 2015) y determinar la edad del componente de carbono. Pigmentos de carboncillo son los materiales más fiables al determinar la edad, aunque solo se puede producir la edad máxima del pigmento (Rowe, 2001). Sin embargo, "la precisión del método de datación con radiocarbono disminuye al aumentar la edad de la muestra” (Sauvet, 2015). La precisión depende de la contaminación del pigmento (Bowen \& Manning, 2003). Un ejemplo destaca un sitio fremont de arte rupestre donde se realizaron pruebas en un pigmento de carboncillo y un artefacto asociado (Geib \& Fairley, 1992). Otro ejemplo de un sitio que sí se pudo datar es el panel Gran Galería en el Parque Nacional Canyonlands. Con una estratigrafía aluvial completa y un evento de desprendimiento de rocas que eran fácilmente fechables, el tiempo de exposición probó que el arte rupestre se fechó a la transición a la agricultura en el altiplano de Colorado (Pederson et al., 2014).

La datación con la termoluminiscencia y la luminiscencia ópticamente estimulada también han probado ser métodos útiles en la datación de arte rupestre. La termoluminiscencia consiste en calentar el material a 275o C y someterlo a dosis de irradiación conocidas para calcular la paleodosis. Esta forma de datación se ha hecho usando depósitos de calcita. Un método similar es la luminiscencia ópticamente estimulada (OSL por sus siglas en inglés). Este método usa la luz en vez del calor para estimular la luminiscencia (Sauvet, 2015). Los investigadores todavía están probando ambos métodos para obtener fechas más precisas.

\section{Trasfondo de investigación}

\section{Definición del papel de la mujer/género en la antropología}

Es importante comprender la diferencia entre género y sexo antes de definir y comprender los roles de género. El sexo se compone de diferencias biológicas determinadas por los cromosomas de una persona. Hay dos sexos: mujer y varón. La sociedad determina el género de una persona, y los resultados de comportamiento significativamente dependen del sexo de uno. "Tal como hay una normalidad natural que crea diferencias a nivel biológico, también hay una normalidad cultural, la cual está ligada a lo que naturalmente hay en una cierta cultura” (Neculaesei, 2015). Algunas sociedades reconocen dos 
géneros-mujeres y hombres-sin embargo, algunas culturas reconocen muchas categorías diferentes. Incluso hay culturas que consideran todos los niños del mismo género hasta llegar a la pubertad o pasar por un rito de iniciación o rito de paso (Hays-Gilpin, 2004b). Mientras el sexo es permanente (genéticamente), el género puede cambiar con el tiempo (Neculaesei, 2015). Por ejemplo, una persona puede nacer mujer basado en la genética y los órganos reproductivos, pero decidir que se identifica como varón más tarde en su vida. $\mathrm{Su}$ sexo sigue igual, pero su género cambia (incluyendo su papel en la sociedad basado en su cultura).

Lee Bader (2014) ofrece tres ejemplos de culturas que incluyen un "tercer género" en Terceros géneros: ¿concepto nuevo? ¿o viejo? En Hawái, antes de su colonización, había una tradición duradera de múltiples géneros, donde el mabu podría ser varón o mujer biológicamente, pero decidir ocupar el papel de género u opuesto al suyo, algo entre los papeles tradicionales de sexo, o hasta ambos roles masculino y femenino. En la antigua cultura incaica, los incas adoraban a un "dios de doble género" conocido como Chuqui Chinchay, quien solo podía ser atendido y honrado por chamanes o sirvientes de tercer género que usaban ropa andrógina como "un signo visible de un tercer espacio que negociaba entre los hombres y lo femenino, el presente y el pasado, los vivos y los muertos." Por último, entre los sakalava de Madagascar, hay un grupo de tercer género reservado especialmente para niños pequeños varones que se consideran tener una apariencia y personalidad femeninas.

Diálogos religiosos, filosóficos y políticos nos transmiten valores y normas. Nos dicen lo que se espera y se acepta para los hombres y las mujeres, y lo que cada género prohíbe. El factor más esencial en la transmisión de género es la comunicación. La comunicación permite a la gente aprender cómo ser hombres y mujeres (Neculaesei, 2015). Las culturas occidentales esperan que las mujeres sean las cuidadoras principales de los niños, mientras se espera que los hombres trabajen y apoyen a la familia. Esta construcción social no es un universal humano, pero es común entre las sociedades patriarcales. Las sociedades matriarcales suelen tener papeles opuestos que las sociedades patriarcales. Los mosuo, ubicados en China cerca a la frontera con Tíbet, son un ejemplo de una sociedad matriarcal. Cada hogar tiene una matriarca encargada, y el lado materno rastrea el linaje familiar. Las mujeres en la cultura mosuo ocupan puestos de liderazgo, lo cual no es el caso en muchas sociedades occidentales (Garrison, 2017; WorldAtlas \& Sawe, 2019). Otras formas de expresión de género incluyen el tipo de ropa uno lleva, la forma en que se comunican y el tipo de trabajo que empeñan. El género de uno determina su papel en la sociedad y surge de los valores y normas culturales de la sociedad, aspectos religiosos y factores históricos y ambientales. Por ende, los roles de género pueden variar significativamente entre sociedades.

\section{Sexo/género y el cosmos en el arte rupestre}

Al estudiar materiales prehistóricos, incluyendo el arte rupestre, es importante tener presente que no podemos imponer roles de género actuales en las culturas del pasado. Debemos interpretar material prehistórico 
individualmente y no aplicar nuestros propios valores y normas culturales a su sociedad. De todas formas, el arte rupestre puede ayudarnos a comprender los roles de género de una cultura porque socializa un paisaje y es una expresión de actividades, valores y normas dentro de una cultura, pero la dificultad queda en sus interpretaciones. Entender la dimensión de género puede ser útil para comprender los roles de sexo/género, patrones de migración, etnogénesis y afiliación cultural. Sea una representación explícita de sexo (genitales) o una implícita, ejemplos distintos de sexo y géneros están presentes en el arte rupestre. La posición de la imagen también puede ser una manera de expresar sexo/género. Por ejemplo, características de una roca, tal como una grieta, pueden ser incorporadas en el arte rupestre para representar una vagina (HaysGilpin, 2004a).

Hay algunos casos cuando el arte rupestre ha desempeñado un papel activo en la diferenciación de género de miembros de una comunidad. Ritos de iniciación de niña a mujer están presentes en imágenes de arte rupestre. Los petroglifos que se encuentran en la meseta del Columbia han ayudado a los arqueólogos a comprender sitios de aislamiento de pubertad y rituales para ambos niños y niñas (Bass, 1994; Hays-Gilpin, 2004a). También hay un ejemplo de las mujeres produciendo y utilizando el arte rupestre para sitios de pubertad en el suroeste de California (Bass, 1994, p. 69; Rogers, 2007, p. 97). $\mathrm{Al}$ arte rupestre también se le conoce por preservar los ritos y dinámica de género dentro de una cultura (Frink et al., 2002).

Otro ejemplo de perspectivas de género comúnmente encontrado en el arte rupestre es la caza. La conexión entre símbolos de masculinidad y armas es una manera posible de representar competición y grabar éxitos al cazar. Richard A. Rogers razona que hay una abundancia de actividad de caza (principalmente varonil) representada en el arte rupestre. Esto es debido a una crisis de dominio de los hombres que ocurrió con el desplazamiento de subsistencia de la caza, una actividad varonil, a la recolección, una actividad femenina. El cambio potencialmente permitió a las mujeres llegar a ser más independientes y los hombres más dependientes de las mujeres y el casamiento, llevando a los hombres a recurrir al chamanismo y presentar sus actividades como significativas por medio del arte rupestre. El problema con esta explicación es que falla en reconocer que la evidencia multicultural no logra apoyar el estereotipo de "hombres son cazadores/mujeres son recolectoras." Sin embargo, puede que algunas diferencias entre las figuras antropomórficas no sean sexo/género, sino diferentes papeles en la sociedad. Hays-Gilpin explica cómo estas diferencias pueden representar algo tan sencillo como guerreros versus no guerreros (Hays-Gilpin, 2004a; Rogers, 2007, p. 79-90).

Mientras que la mayor parte del arte rupestre antropomórfico carece de atributos de sexo, es esencial notar algunas distinciones de sexo. Símbolos por genitales masculinos pueden incluir una línea entre las piernas o un bulto al extremo o dos puntos por los testículos. Símbolos por genitales femeninos incluyen un punto o una cúpula, dos líneas cortas, tres líneas cortas, un triángulo o una combinación entre las piernas (Hays-Gilpin, 2004a). Una 
norma en el arte rupestre, especialmente el arte que se encuentra en Norte América, es la ausencia aparente de mujeres. No obstante, si pudiéramos mejor interpretar el arte, podría ser que no sea el caso. Un problema que se presenta al intentar fijar el género de una figura antropomórfica es la mutabilidad de género, lo cual es común entre algunas culturas de nativo americanos (HaysGilpin, 2004a; Rogers, 2007, p. 89-96).

En cuanto a símbolos de género en el arte rupestre, Patricia Bass explica cómo la "desgenerización" del arte rupestre no significa una falta de presentación de género, pero "si el género es importante, entonces no todas las representaciones deben ser de varones" (Bass, 1994, p. 10). "Desgenerizar" es quitar cualquier suposición o sesgo que no puede tener en cuanto a género/ roles de género al intentar interpretar el arte rupestre. Al "desgenerizar" el arte, no imponemos nuestros roles de género en culturas del pasado. Bass sigue explicando cómo la comúnmente usada hipótesis "chamánica” puede ser problemática. Si empleamos esta hipótesis, necesitamos estar conscientes de símbolos de perspectiva de género dentro de las costumbres chamánicas también. Además, puede haber otros motivos sexuales que se nos pasan por alto si suponemos que el arte se originó de costumbres chamánicas (Bass, 1994).

Un estudio de Catherine Namono (2005) sobre los asuntos femeninos encontrados en un sitio soto en el norte de Sudáfrica destaca la importancia de usar la investigación etnográfica para interpretar el arte rupestre más eficazmente. Investigación previa sobre el arte solo se ha enfocado en ritos de iniciación de niños varones y representaciones de arte de contrato colonial. Mucho del arte del sitio incluyó figuras geométricas e imágenes que se parecen a prendas de vestir principalmente llevadas por mujeres. Después de usar etnografías, podían vincular el arte a artistas mujeres y suponer que cualquier arte geométrico del área esté relacionado con las mujeres ya que las imágenes pueden representar implícita o explícitamente los asuntos femeninos, tal como la menstruación y el parto. Namono hace hincapié en la importancia de autoría al interpretar el arte rupestre (Namono \& Eastwood, 2005, p. 77).

Otro aspecto necesario para entender el arte rupestre es el cosmos, el cual es instrumental en muchas religiones y culturas. El cosmos significa "mundo ordenado" y representa una manera de acercarse a un dios o "gran creador" para muchas religiones (Mullen, 2011). Muchas religiones creen en un cosmos estratificado que representa diferentes niveles de vida y espiritualidad. El cosmos estratificado tiene un mundo inferior, intermedio y superior. El mundo inferior normalmente se asocia con la muerte, el nacimiento, los antepasados y el peligro, el mundo intermedio representa la superficie de la tierra, y el mundo superior típicamente es el cielo y los cuerpos celestiales. Para viajar entre los mundos, hay un sendero conocido como el axis mundi que conecta los mundos del universo (Wright \& Russell, 2011).

Encontrada multiculturalmente por el suroeste de Norte América, la pipeta es un motivo del arte rupestre poco común representando un cosmos estratificado. Muchas explicaciones etnográficas de la pipeta tienen un tema 
común: la religión, la conexión a otro lugar y la transcendencia. Wright y Russell afirman que la pipeta sin duda es un símbolo religioso debido a su prominencia, visibilidad, asociación con santuarios y contexto astronómico (Wright \& Russell, 2011). Las pipetas y el arte rupestre, por lo general, pueden ser esenciales para comprender el cosmos de una cultura (Namono, 2012) y cómo ven su posición en el mundo.

Otro símbolo común que los arqueólogos creen representa el cosmos son mancuernas y círculos concéntricos encontrados en el arte rupestre pigmeo de Uganda. Catherine Namono razona que las mancuernas representan los genitales varoniles, y que los círculos concéntricos representan los genitales femeninos. La conclusión saca información de una combinación de cosmología y análisis etnográfico. Este ejemplo es útil para entender cómo las etnografías ayudan a mejor explicar el arte rupestre prehistórico (Namono, 2012).

\section{El papel de la mujer en el arte rupestre}

Ya sea en su representación o autoría, el papel de la mujer en el arte rupestre todavía no queda claro y es raras veces investigado. Esto puede ser debido al hecho de que procesos más amplios a nivel de sistema fueran de más interés (Wylie, 2002). También podría ser debido a la arqueología como profesión siendo principalmente hombres $y$, por ende, enfocada en expresiones de masculinidad (especialmente en cuanto a la caza). A la mayor parte del arte rupestre antropomórfico le faltan atributos sexuales. Los genitales masculinos se han representado como una línea entre las piernas con un bulto ocasional al extremo y dos puntos por testículos. Los genitales femeninos a veces se expresan como punto/cúpula, dos líneas cortas, tres líneas cortas, un triángulo o una combinación de símbolos entre las piernas de la figura antropomórfica.

También es difícil determinar si la variación de las figuras antropomórficas representan el género o rol (Hays-Gilpin, 2004b). Por ejemplo, ¿podrían dos figuras con diferentes formas de cabeza representar género? Posiblemente, pero también podrían representar un chamán versus un no chamán, un guerrero versus un no guerrero, o un niño versus un adulto. Sin la incorporación etnográfica, no podemos decir por seguro que se han representado diferencias de varones y mujeres.

Otra razón que "generizar" el arte rupestre puede resultar problemático es la creencia androcéntrica que la única función de la mujer es la reproducción. Es opresivo, pero comúnmente se asume que cualquier arte rupestre que representa una mujer va a centrarse en la reproducción, el parto y el cuidado de niños (Handsman, 2002). También se apoya en la creencia que el papel de la mujer en la sociedad no ha cambiado desde que se creó el arte rupestre (Wylie, 2002). A menos que la investigación etnográfica provea roles definidos para la mujer en una sociedad, no podemos suponer que sus roles eran los mismos que los de la mujer moderna. 


\section{Métodos}

\section{Repaso de literatura y recopilación de datos}

Para esta investigación, completé un repaso de literatura existente para evaluar las maneras en que el género se encuentra o se expresa en el arte rupestre en Utah. Engendrar la arqueología de Margaret W. Conkey y Joan M. Gero (2002) e Imágenes ambiguas de Kelley Hays-Gilpin (2004a) fueron libros claves. El primer libro provee una manera para mejor comprender cómo el género encaja en la arqueología. El segundo libro fue útil para comprender la ambigüedad del arte rupestre. Lo que quiere decir esta lezna de Janet D. Spector (1993) sirvió de fundamento útil en mi investigación para entender cómo las inclinaciones pueden afectar la investigación arqueológica.

Se completó la recopilación de datos de información específica de un sitio con la ayuda del Director de Documentos Arqueológicos de la Sección de Antigüedades dentro de la División de Historia Estatal de Utah. Como repositorio central para la información de sitios arqueológicos en Utah, la Sección de Antigüedades mantiene documentos de más de 100,000 sitios arqueológicos conocidos, incluyendo el arte rupestre. El director de documentos realizó una búsqueda de sitios en la base de datos comprensiva arqueológica basada en localidad espacial y tipo de sitio. Primero, en conversaciones con el director de documentos, era importante restringir el alcance del proyecto propuesto a unos cuantos condados en el noroeste de Utah. La búsqueda, por ende, se restringió a los condados de Box Elder, Carbon, Juab, Millard, Tooele y Utah. Desde el entorno de esos condados, la búsqueda se redujo más según características prehistóricas: petroglifos y pictografías. La búsqueda resultó en 751 formas de sitios que se revisaron para cualquier indicio de atributos de sexo/género. Para la referencia del autor, los sitios arqueológicos en Utah usan un sistema trinomio del Smithsonian lo cual quiere decir que los primeros dos números son el código del estado de Utah (42), seguidos por un código de dos letras para el condado (BO por Box Elder por ejemplo) y después una serie secuencial de números que indica qué número de sitio es para ese condado (así que 2300 es el sitio dos mil trecientos que se ha documentado en ese condado).

\section{Métodos cualitativos}

Los métodos cualitativos incluyeron análisis de sitios, incluyendo atributos de sexo/género. Este método probó ser la manera más importante para determinar la cantidad de atributos de sexo/género encontrados entre el arte rupestre en Utah.

\section{Métodos cuantitativos}

Métodos cuantitativos incluyeron contar el número de sitios de arte rupestre mostrando atributos de sexo/género. Solo aproximadamente 3\% de los sitios incluyeron posibles atributos de sexo/género. 


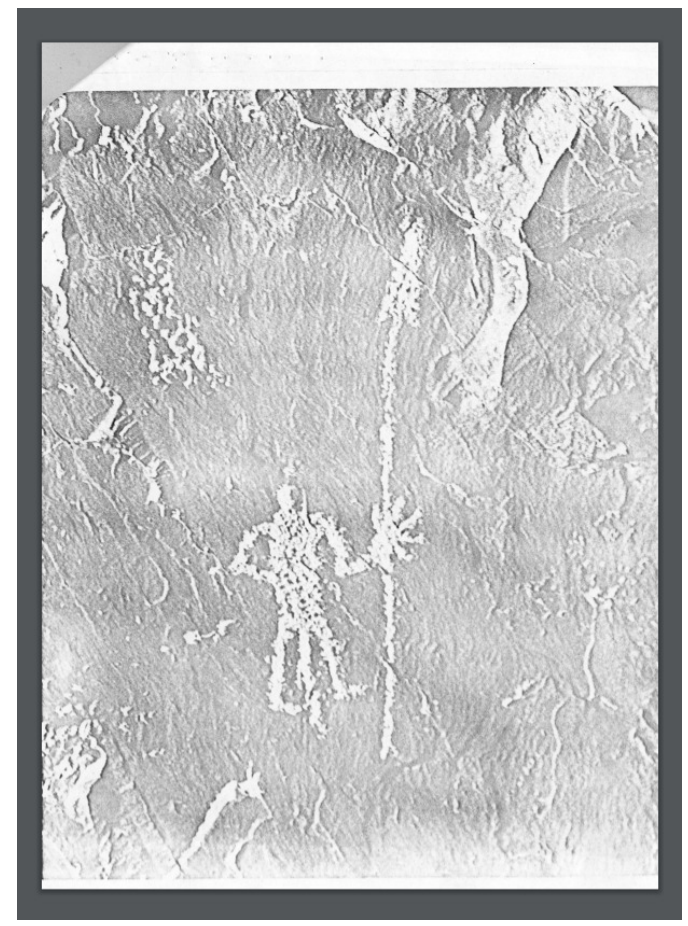

Figura 1. Antropomorfo con una línea entre piernas y una lanza en mano.

\section{Resultados}

\section{Observación del arte rupestre}

$\mathrm{Al}$ repasar las formas de los sitios, se notaron los siguientes sitios basado en cualquier atributo de sexo/género que contenían. Los atributos incluyeron los genitales (líneas extras entre las piernas, dos puntos por los testículos, cúpulas, etc.) y círculos concéntricos. Aunque es probable que haya más arte rupestre con representación de género que lo listado abajo, estos eran los más obvios. Lo siguiente son ejemplos de posible representación de género en el arte rupestre en seis condados de Utah basado en el tipo de atributo de sexo/género.

\section{Antropomorfos con líneas entre sus piernas}

Sitio 42BO386, presentado abajo, incluye una figura antropomórfica con una línea entre las piernas. La figura tiene una mano portando una lanza y tiene extremidades. La línea entre las piernas es más larga que las piernas originales y no tiene pie como las otras. Esto podría representar una variedad de cosas: una tercera pierna, una cola o un pene. Sin embargo, si fuera una cola, lo más probable es que estaría a un lado tal como está en sitio 42BO1703. Si fuera tercera pierna, probablemente tendría la misma longitud que las otras dos piernas. Aunque la tercera línea bien podría ser una cola, tercera pierna, o algo desconocido, también parece lógico que representa un pene (Barger, 1978; Stuart, 2007a).

Sitio 42BO2114 incluye dos figuras antropomórficas con una sola línea, más pequeña entre las piernas. La segunda figura (Figura 3) tiene un bulto en el extremo de la línea (Stuart, 1985). 


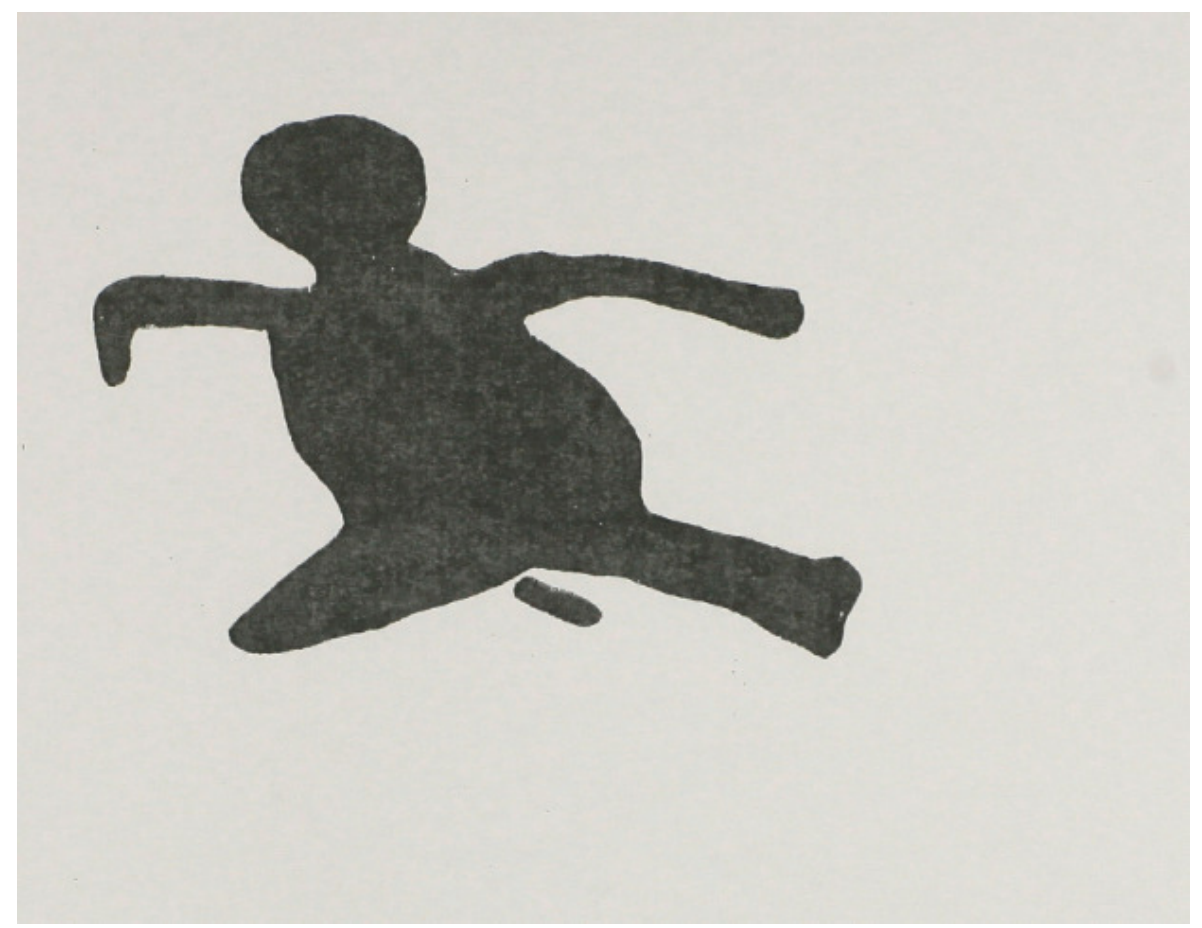

Figura 2. Antropomorfo con una línea entre las piernas.

Fuente: Stuart (1985)

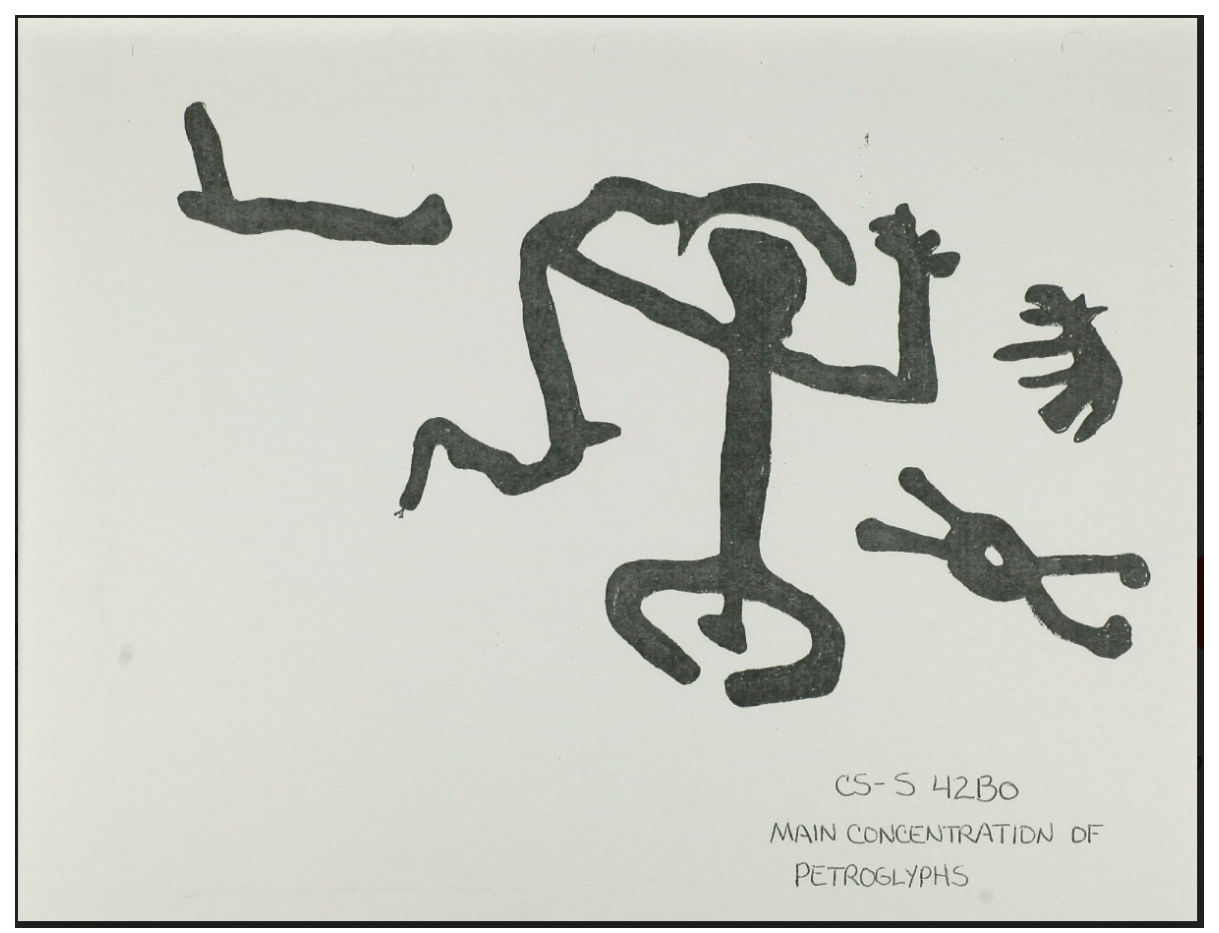

Figura 3. Antropomorfo con una línea y un bulto entre las piernas.

Fuente: Stuart (1985)

Sitio 42CB958 muestra otro ejemplo de una figura con una línea entre las piernas, extremidades, y una cabeza en forma de aro. La figura tiene una forma de cuerpo interesante también (Spangler, 2007). 


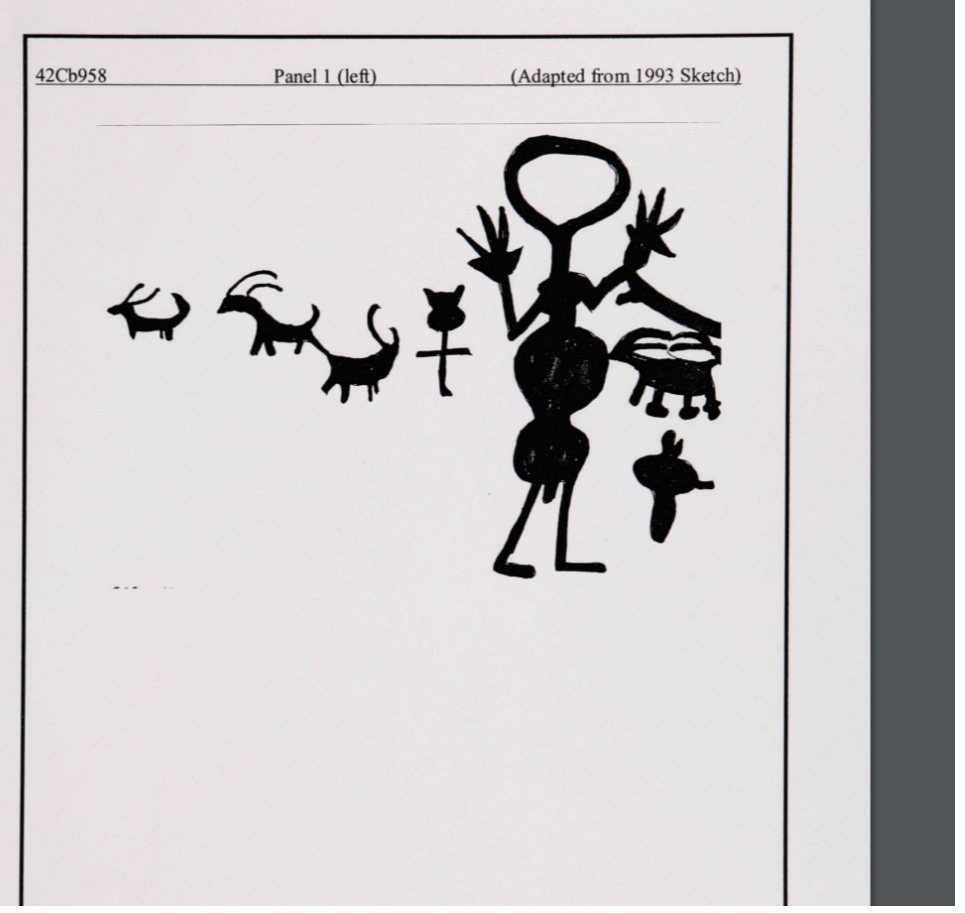

Figura 4. Antropomorfo con una línea pequeña entre las piernas.

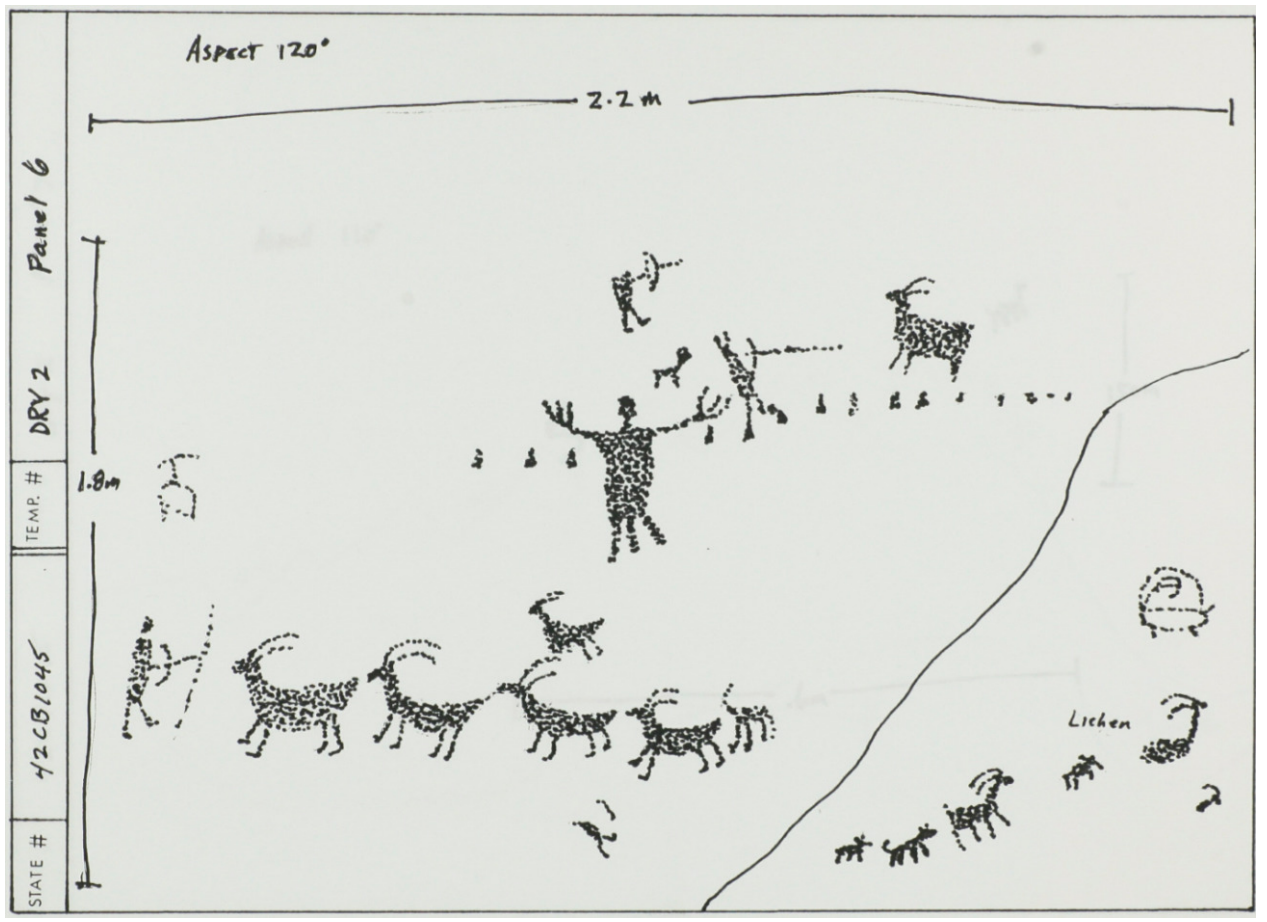

Figura 5: Antropomorfo con una línea entre las piernas.

Fuente: Miller (1996)

Sitio 42CB1045 es otro ejemplo de una figura antropomórfica con una línea entre las piernas (Miller, 1996). 


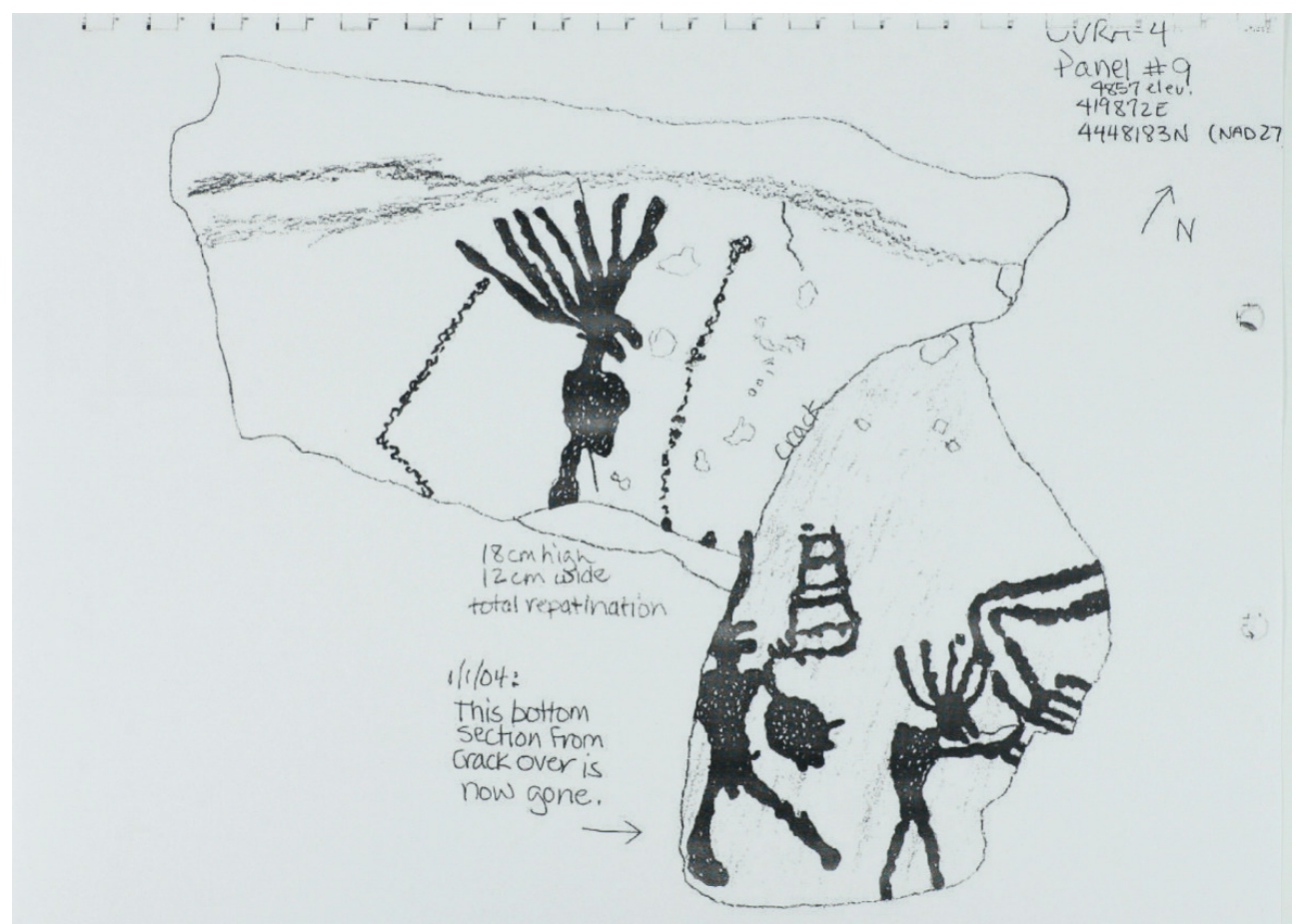

Figura 6. Tres antropomorfos, uno con una línea entre las piernas.

Fuente: Healy (1999)

Sitio 42UT1586 representado en el dibujo abajo muestro un panel de arte rupestre en petroglifo en el condado de Utah. Hay tres figuras antropomórficas representadas. Las tres figuras tienen formas similares de cuerpo y cabeza; sin embargo, la figura a la izquierda parece solo tener una pierna y ningún brazo. La figura en el centro tiene una línea pequeña entre sus piernas, la cual puede ser símbolo de un varón (Hays-Gilpin, 2004a; Healy, 1999).

\section{Antropomorfos de varios tamaños y formas}

Sitio 42BO400 muestras unos diez antropomorfos diferentes de varios tamaños y formas. Las formas de cuerpo y tamaños variados pueden no tener significancia, pero también podrían representar diferentes sexos ya que biológicamente, los hombres típicamente son más grandes que las mujeres. Mark E. Stuart primero documentó este sitio en 1982. He incluido sus dibujos originales abajo como referencia (Stuart, 1982).

Sitio 42BO1703, con sobrenombre Table Rock, tiene antropomorfos con formas de cabeza interesantes y uno posiblemente con una cola y una apariencia demoníaca (Stuart, 2007a).

Sitio 42BO412 es otro ejemplo de antropomorfos de diferentes tamaños, posiblemente representando diferencias de sexo o adultos y niños. La imagen muestra lo que probablemente es un adulto y un niño debido a las diferencias significantes de tamaño (Stuart, 1982). 


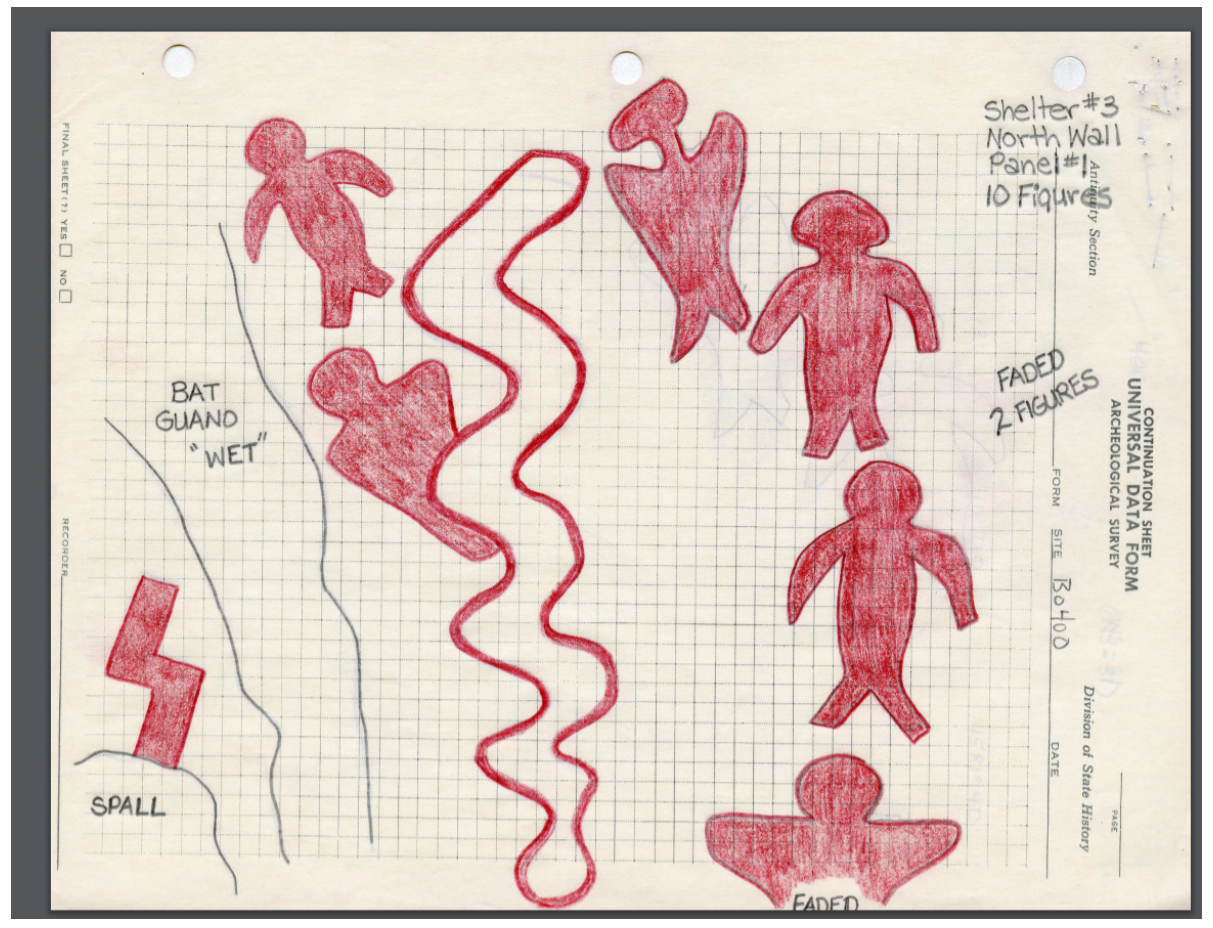

Figura 7. Variedad de tamaños y formas.

Fuente: Stuart (1982)

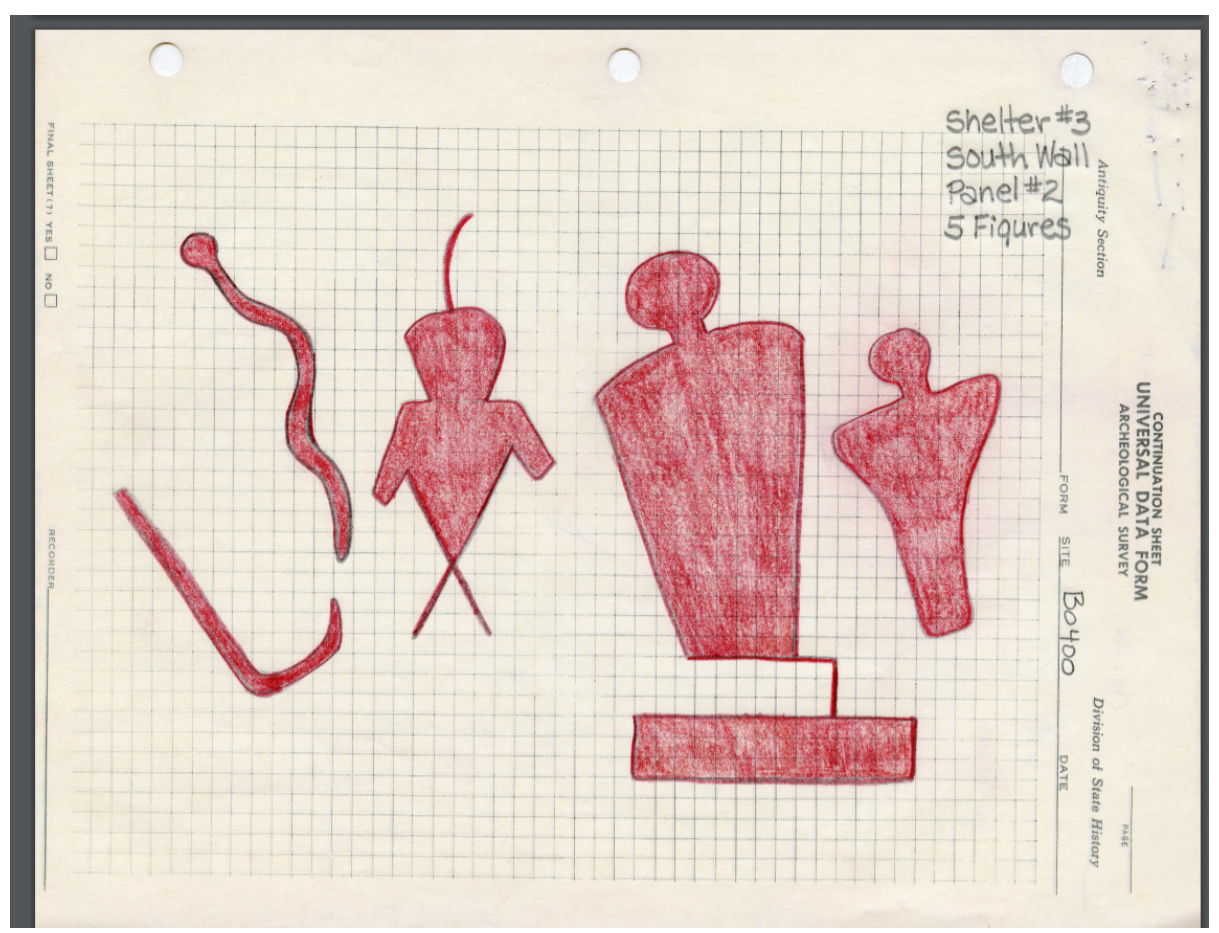

Figura 8. Variedad de tamaños y formas.

Fuente: Stuart (1982) 


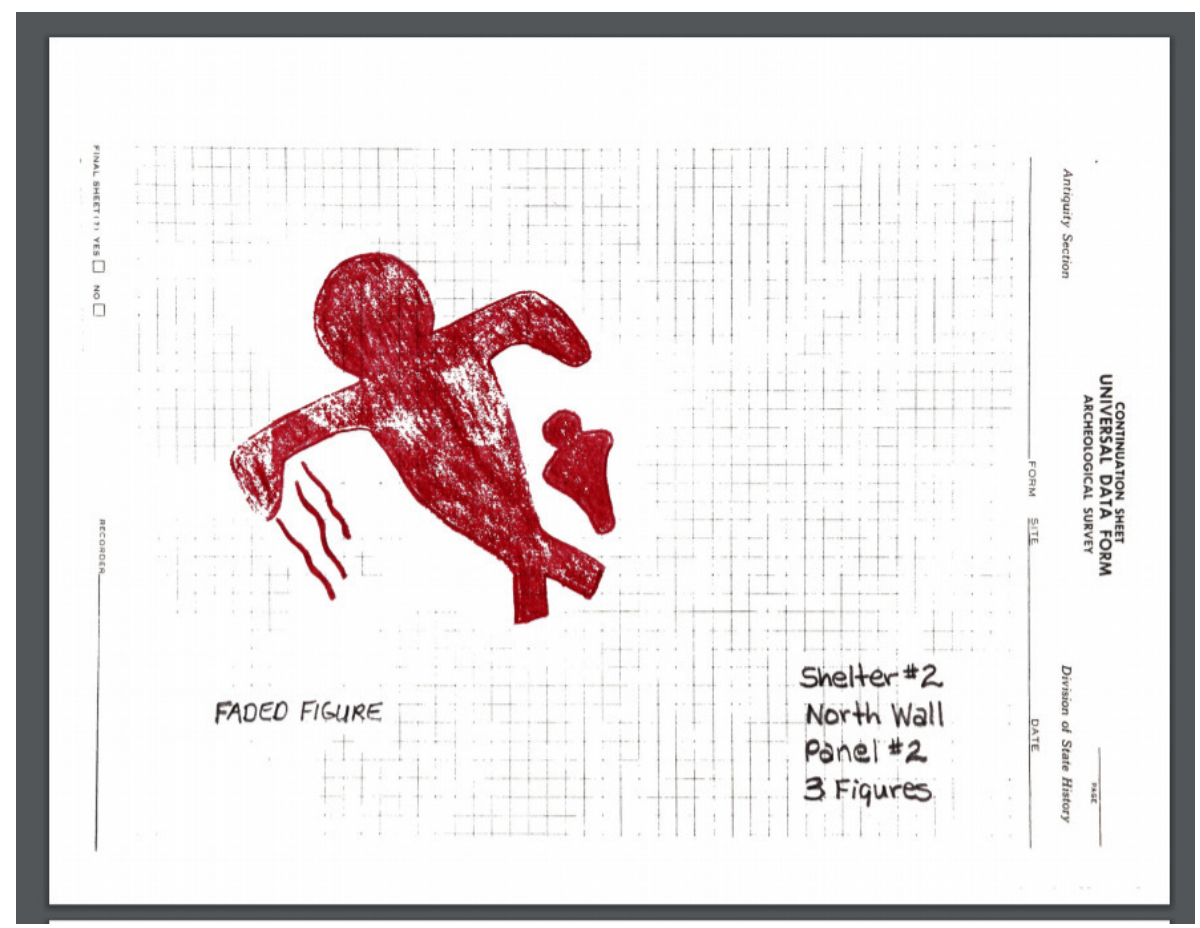

Figura 9. Adulto y niño.

Fuente: Stuart (1982)

Sitio 42BO1705, con sobrenombre Roca Hombre Grande/Hombre Pequeño, incluye una figura posiblemente de un adulto y un niño conectados por un objeto circular. El registrador notó que el objeto circular podría ser un escudo. Otra vez, las diferencias de tamaño podrían ser por edad o representaciones de género (Stuart, 2007a).

Sitio 42UT1784 incluye antropomorfos de diferentes tamaños, posiblemente representando varias edades o géneros. La figura más pequeña parece tener una línea entre las piernas (Manning, 2011).

Sitio 42BO1707 tiene un panel con un grupo de tres antropomorfos de varios tamaños (Stuart, 2007b).

\section{Antropomorfos con diferentes formas de cabeza}

Sitio 42BO582 muestra antropomorfos posiblemente agarrados de las manos con diferentes formas y tamaños de cabeza. Lo de las manos agarradas podría simbolizar la conectividad o una relación intersexual (Stuart, 1986).

Sitio 42BO1703, con sobrenombre Table Rock, tiene antropomorfos con formas de cabeza interesantes y uno posiblemente con una cola y una apariencia demoníaca (Stuart, 2007a).

Sitio 42BO1707, con sobrenombre Roca de Hombre Rana, incluye una figura que es teriantropomórfica con una cabeza como rana y extremidades en el panel principal (Stuart, 2007b).

Sitio 42TO160 tiene un panel con tres antropomorfos de diferentes formas y tamaños. Dos de las figuras tienen una línea entre las piernas, posiblemente representando los genitales varoniles. Todas las formas de cabeza de los antropomorfos también varían (Cartwright, 1979b). 


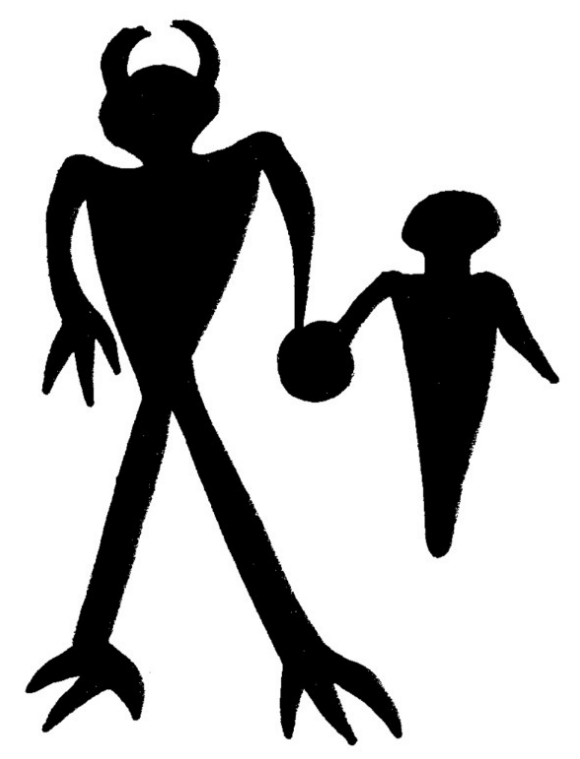

Figure 10. Roca Hombre Grande/Hombre Pequeño

Fuente: Stuart (2007a)

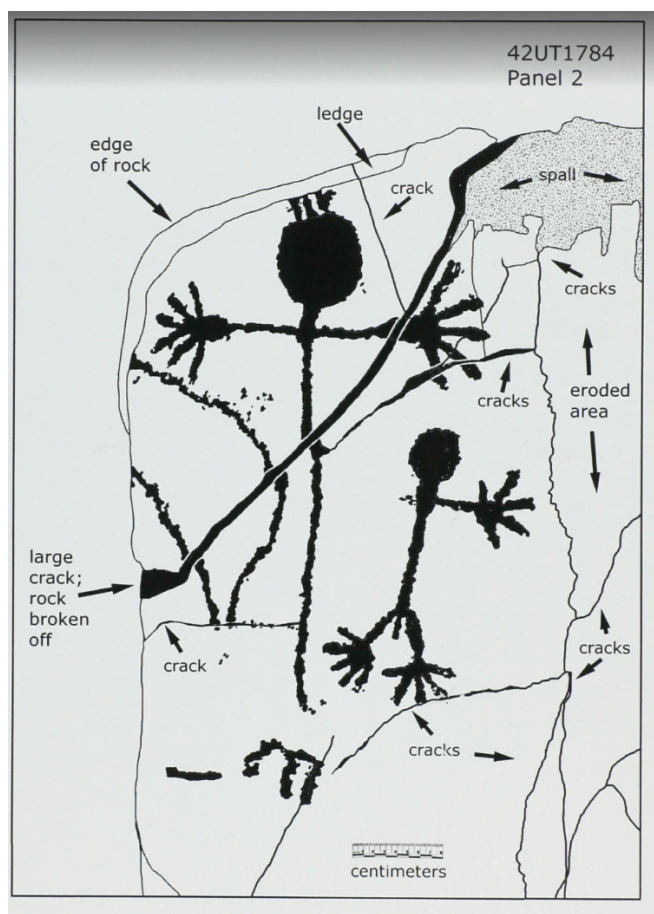

Figura 11. Dos antropomorfos de diferentes tamaños, uno con una línea entre las piernas. Fuente: Manning (2011) 
Figure 76: Close up view and sketch of more petroglyphs on west side of Burnt Rock

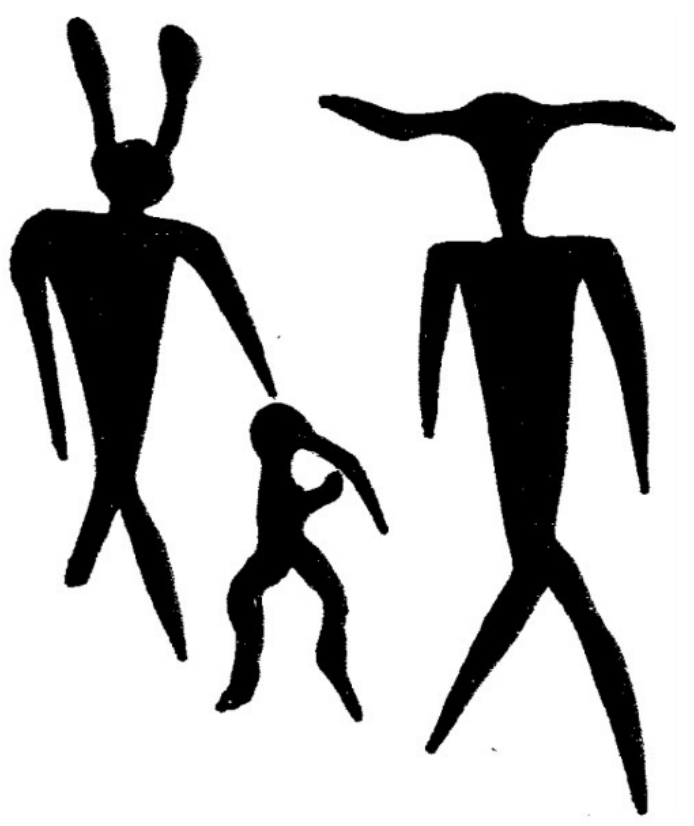

Figura 12. Familia de antropomorfos.

Fuente: Stuart (2007b)

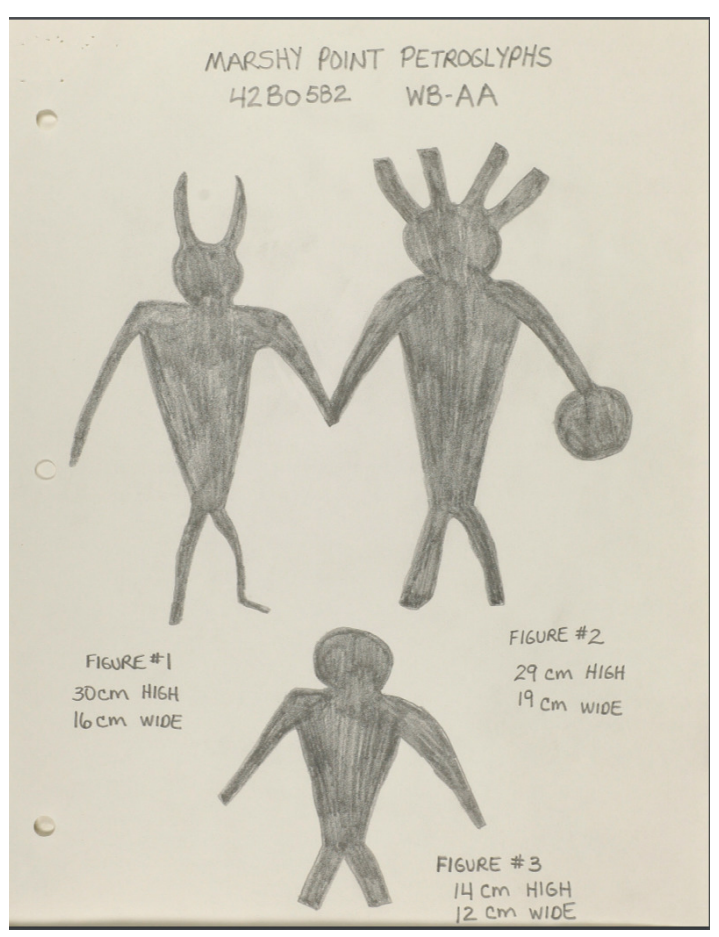

Figura 13. Antropomorfos agarrados de las manos

Fuente: Stuart (1986) 
Figure 67: Photo and sketch of Table Rock petroglyphs.

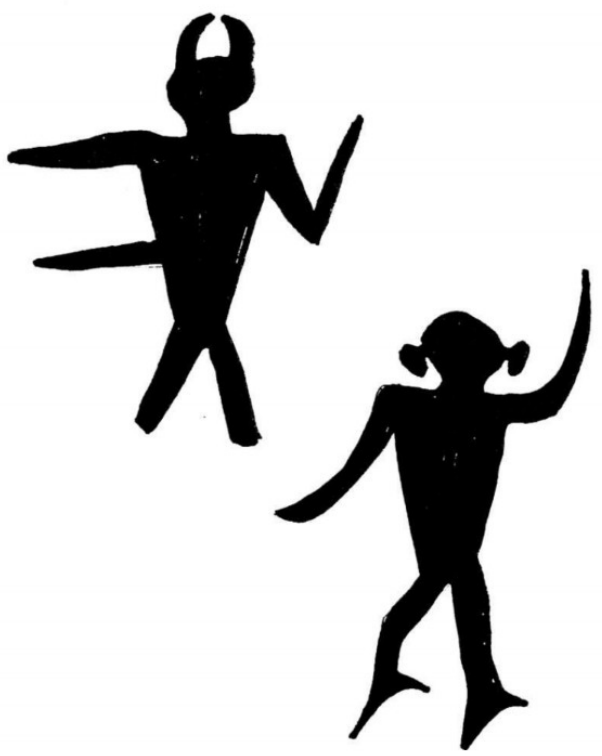

Figura 14. Dos antropomorfos con diferentes formas de cabeza

Fuente: Stuart (2007a)

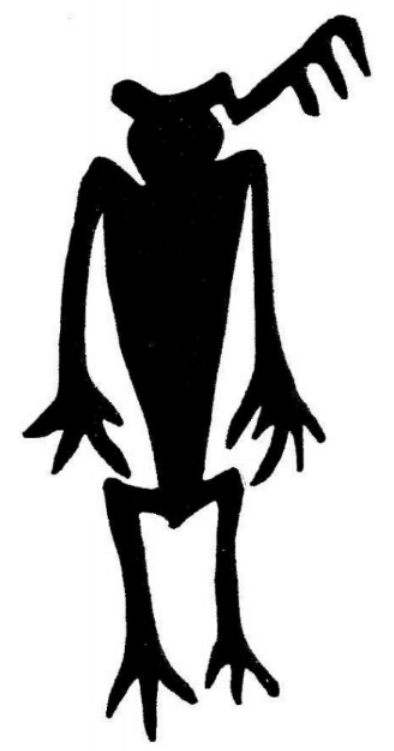

Figure 72: Sketch of Frogman petroglyph.

Figura 15. La roca del Hombre Rana.

Fuente: Stuart (2007b) 


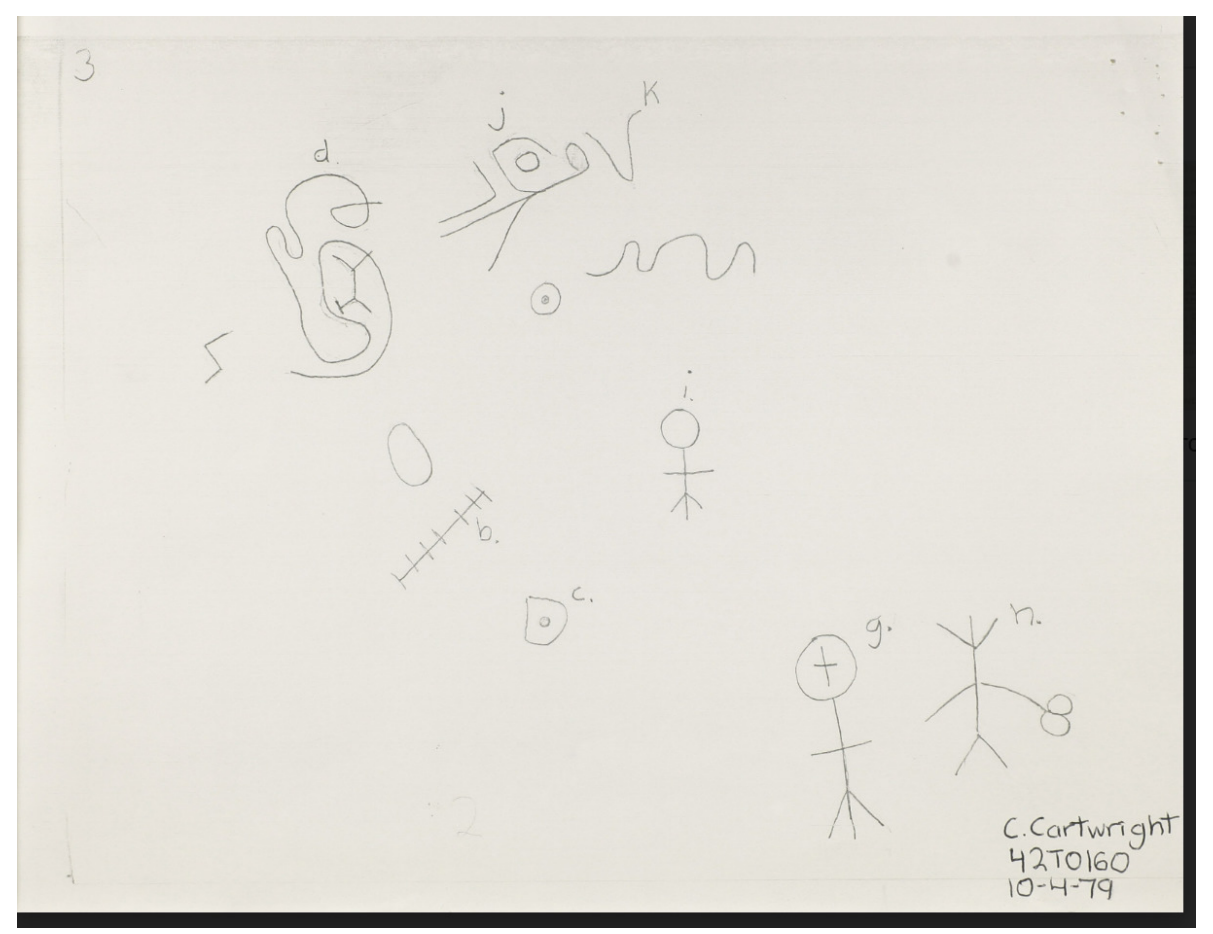

Figura 16. Formas de cabeza variadas.

Fuente: Cartwright (1979b)

\section{Círculos concéntricos y cúpulas}

Sitio 42BO412 incluye dos antropomorfos. Una figura tiene cúpula debajo de ella, lo cual es símbolo característico de los genitales femeninos en el arte rupestre (Hays-Gilpin, 2004a; Stuart, 1982).

Sitio 42JB126 muestra múltiples antropomorfos alrededor de círculos concéntricos. Los círculos pueden representar la fertilidad de la mujer con el tiempo (Hays-Gilpin, 2004b; KBO, 1974).

Devil's Kitchen en el condado de Millard incluye muchos paneles con círculos concéntricos (Shipley, 2019).

Sitio 42TO209 muestra una figura grande antropomórfica con círculos concéntricos a su alrededor además que una segunda figura. Ambas figuras tienen cuernos (Cartwright, 1979a).

Sitio 42UT1746 incluye un panel con picoteos de múltiples cúpulas, las cuales podrían representar una vulva o vagina (Hays-Gilpin, 2004a; Shipley, 2019).

\section{Análisis}

\section{Análisis del estudio}

Más de 750 formas de sitios se examinaron para buscar cualquier indicio de atributos de género o sexo. Mientras había una cantidad adecuada de antropomorfos, también había muchas teriantropías, antropomorfos con cabezas, o extremidades, animales (Solomon, 1997). No había muchos paneles que mostraban atributos de género. Si el estudio incluyera, por ejemplo, Moab en el condado Grand, habría más paneles representando los roles de género. 


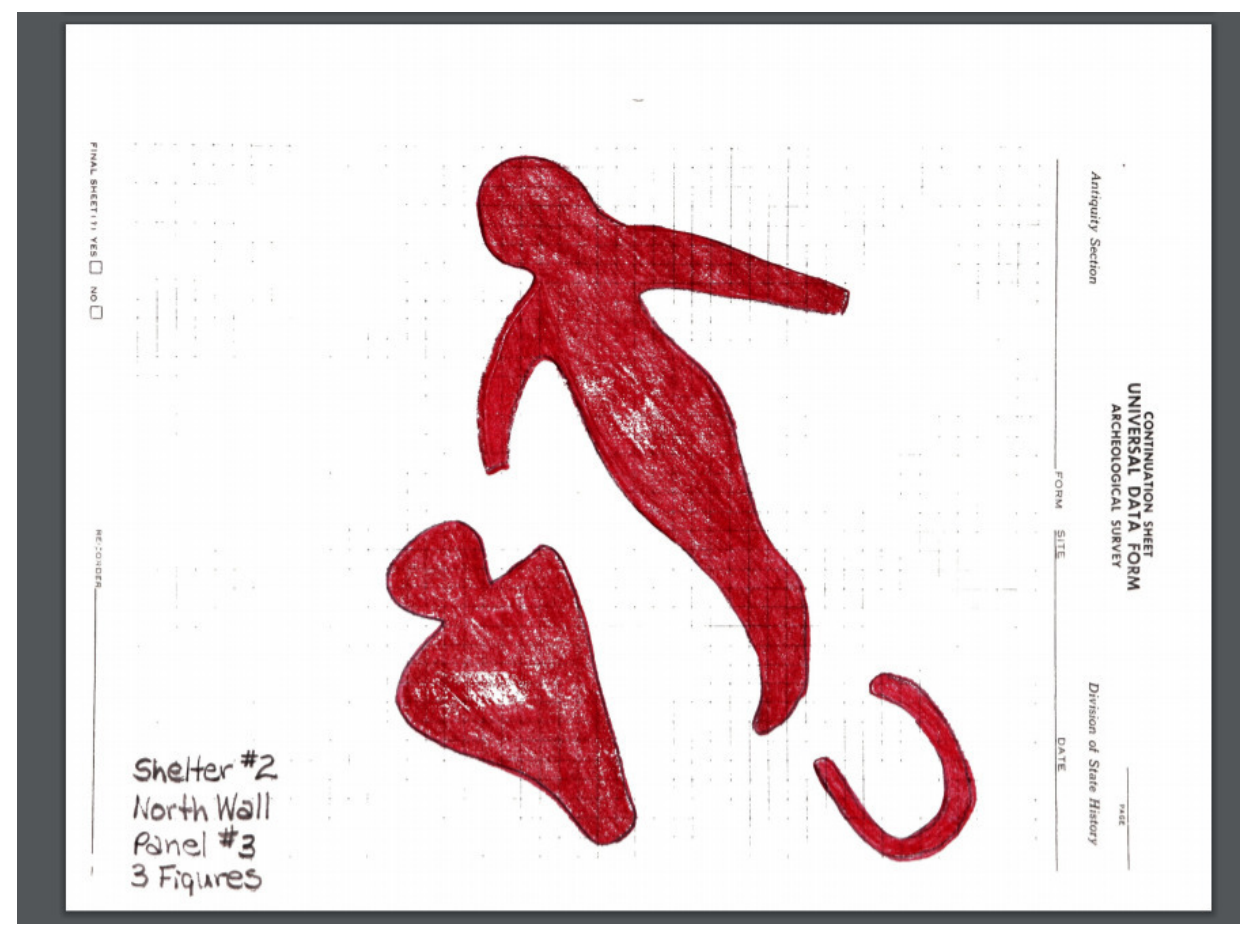

Figura 17. Cúpula.

Fuente: Stuart (1982)

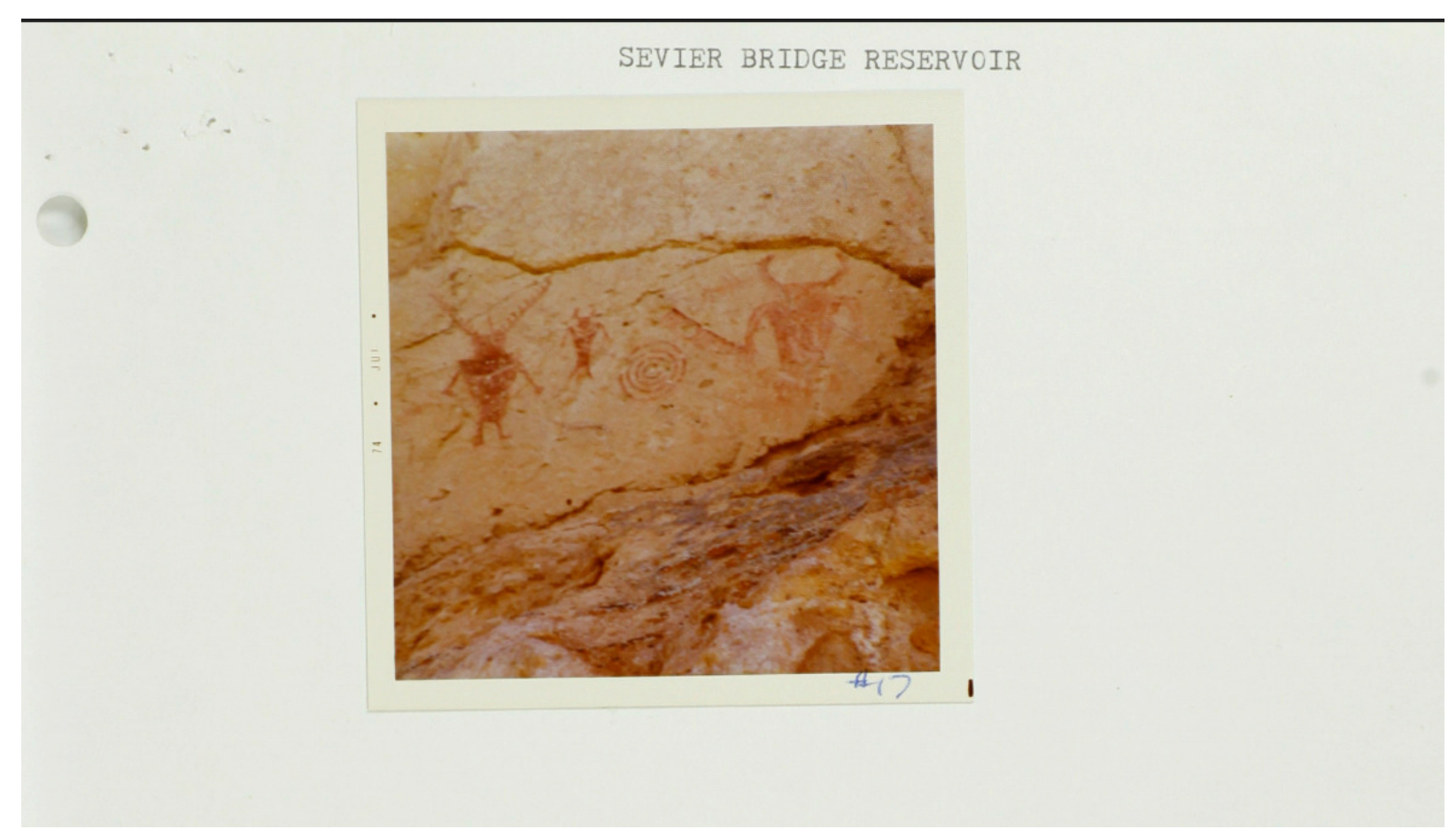

Figura 18. Círculos concéntricos.

Fuente: KBO (1974)

"La roca del parto" en Moab (Figura 25) es un ejemplo de arte rupestre que claramente representa las mujeres y el papel de la mujer ("Petroglifos y sitios de arte rupestre-descubre Moab, Utah,” 2017). Otros sitios populares de arte 


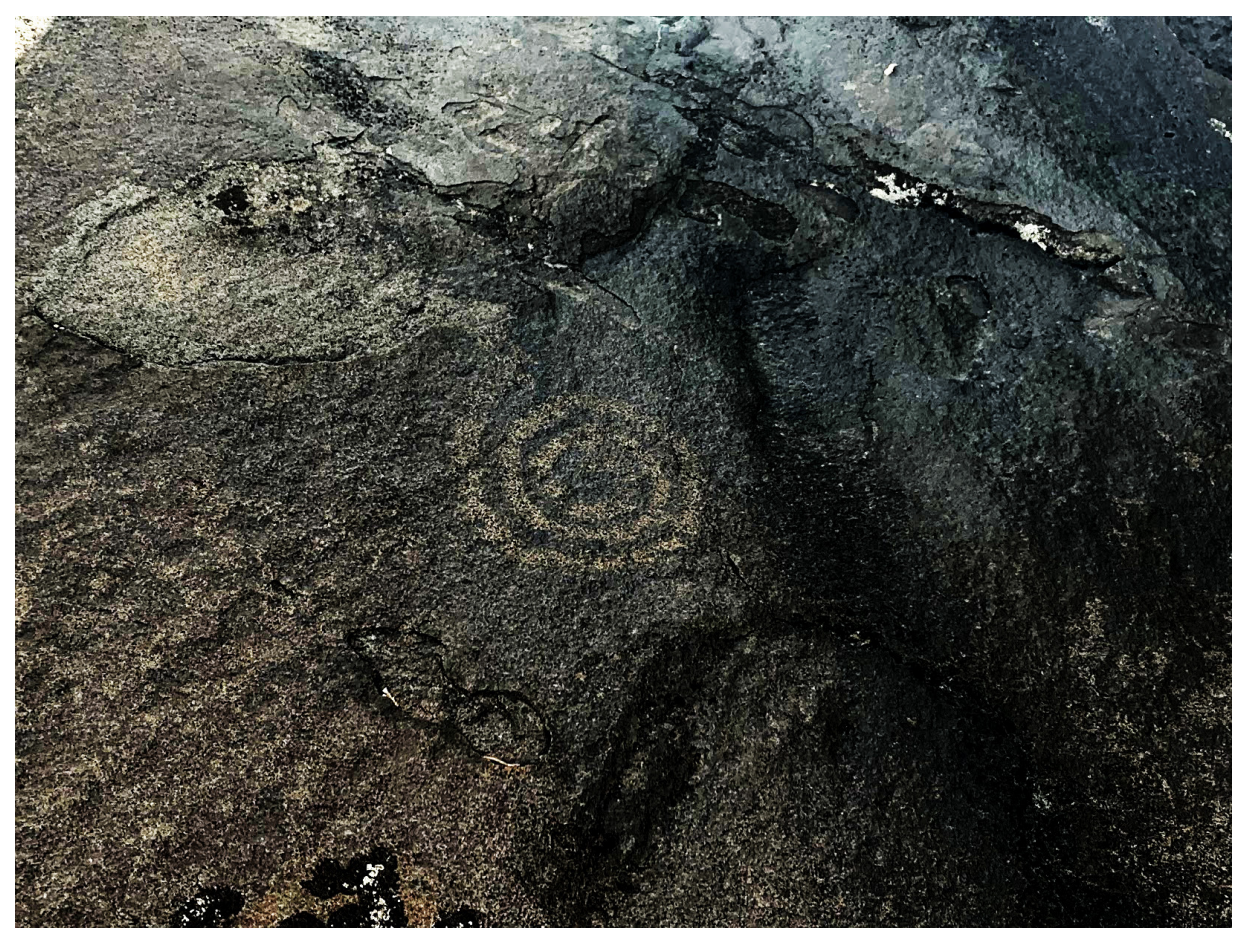

Figura 19. Más círculos.

Fuente: Shipley (2019)

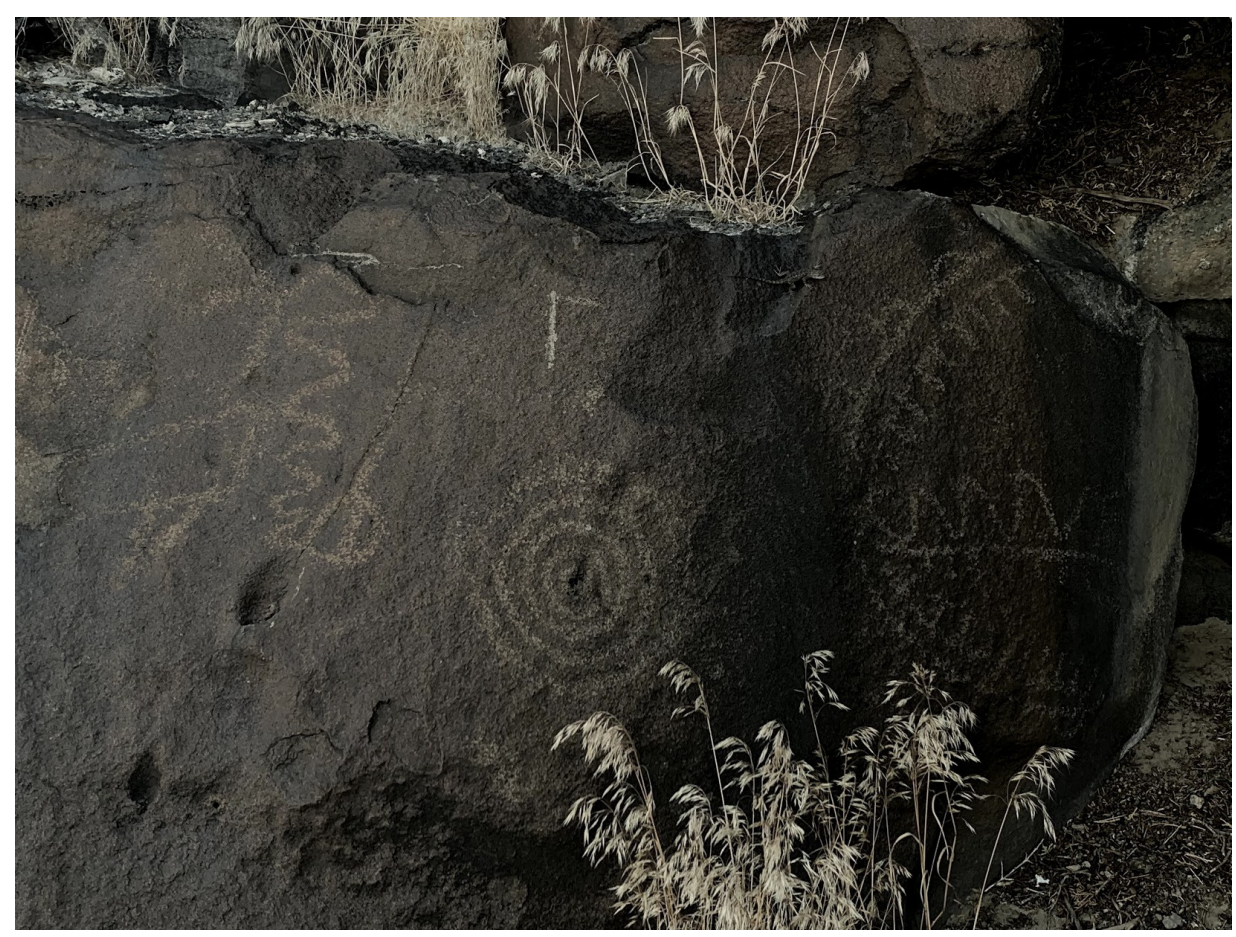

Figura 20. Más círculos.

Fuente: Shipley (2019) 


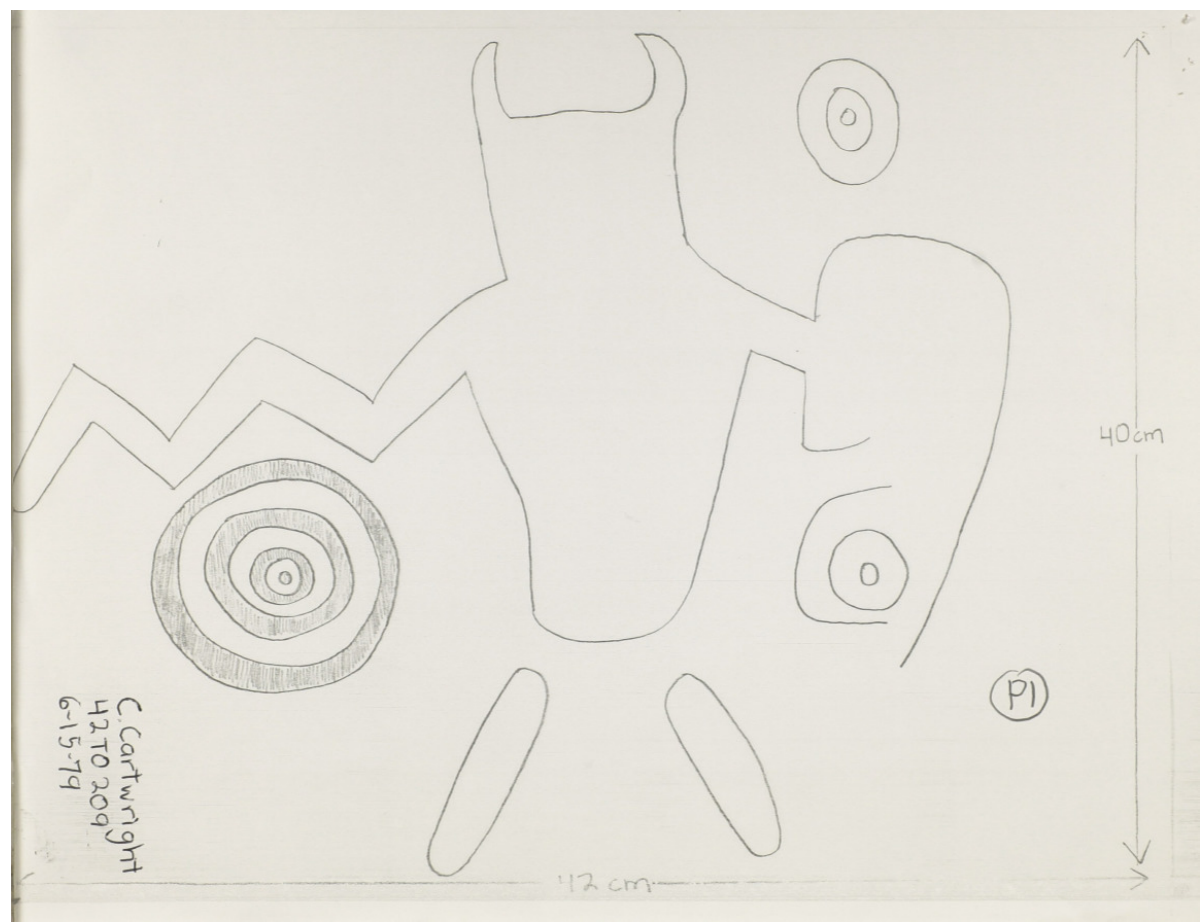

Figura 21. Antropomorfos con círculos.

Fuente: Cartwright (1979a)

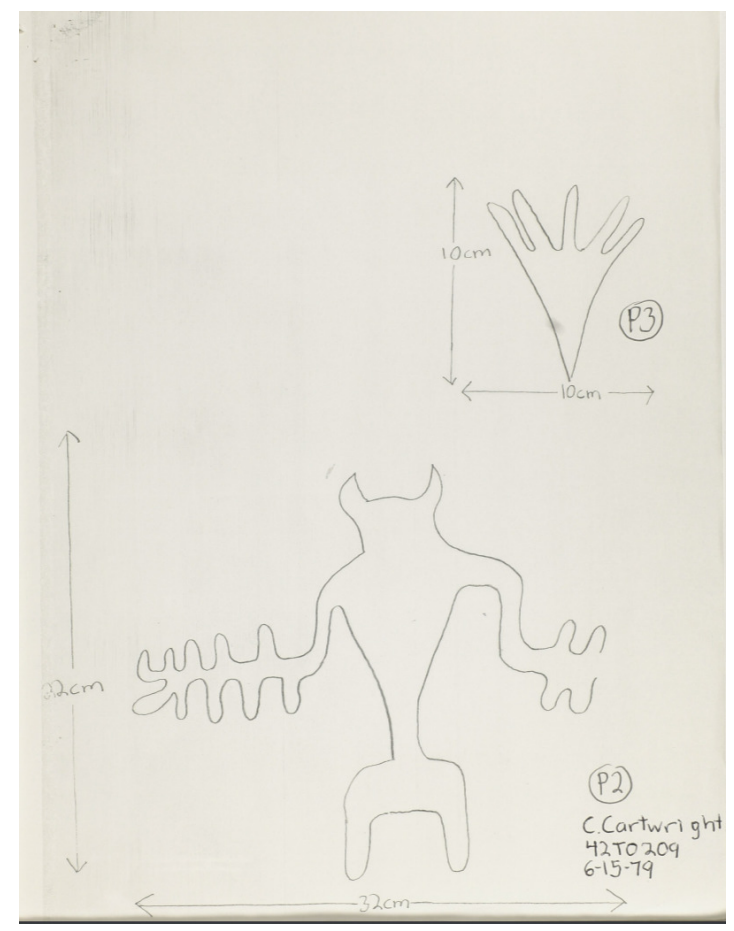

Figura 22. Antropomorfos con círculos.

Fuente: Cartwright (1979a) 


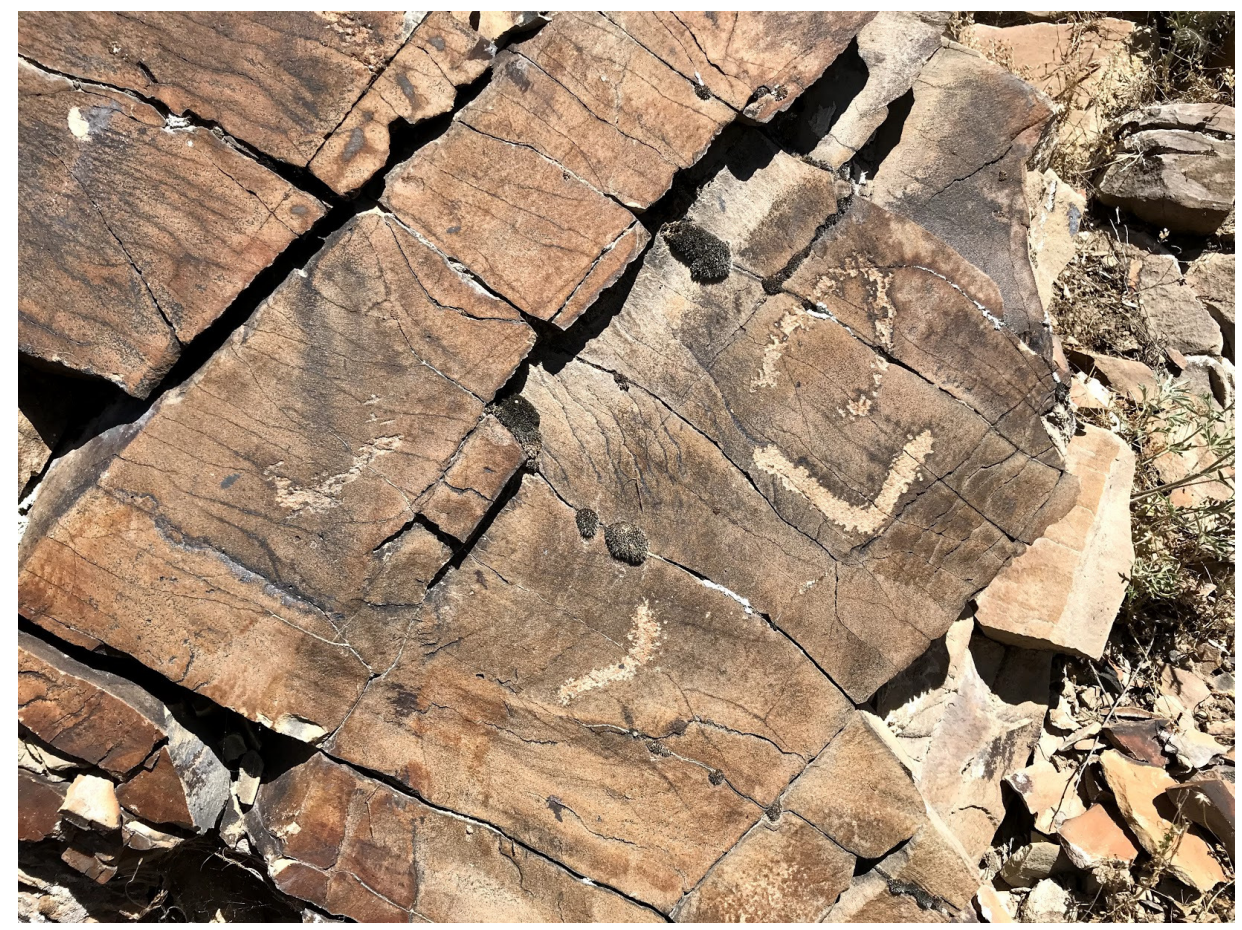

Figura 23. Unas cúpulas.

Fuente: Shipley (2019)

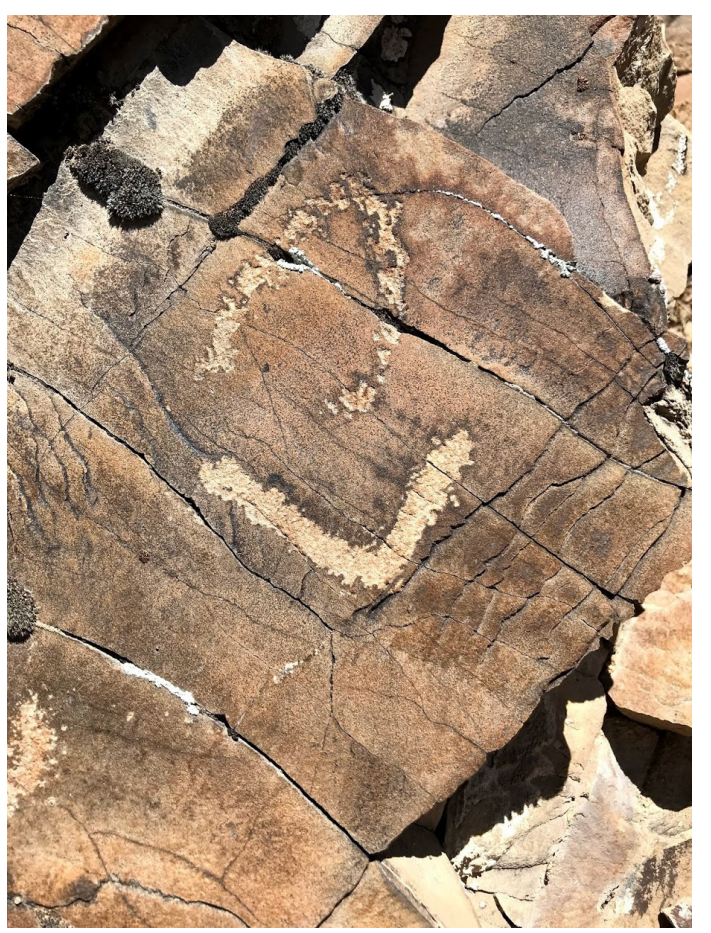

Figura 24. Unas cúpulas.

Fuente: Shipley (2019) 


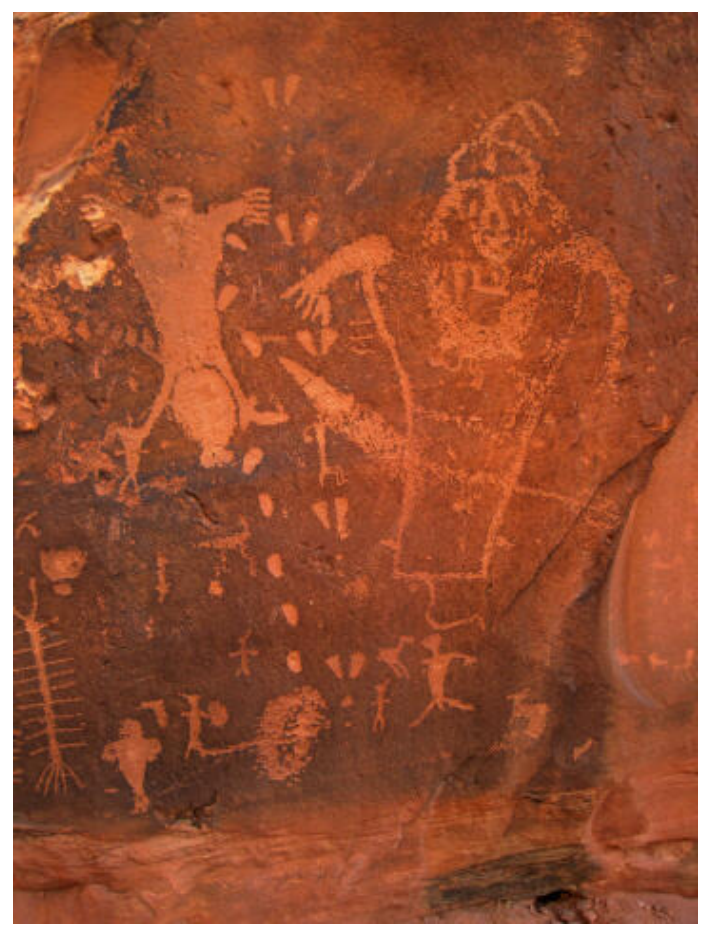

Figura 25.

Fuente: Birthing Scene (2000)

rupestre en Utah se pueden encontrar en el sitio web de URARA. Hay unos 4200 sitios de arte rupestre documentados en Utah, así que probablemente hay muchos más que representan los roles de género/sexo (Scotter \& Bowen, 2019).

Las atribuciones de género son difíciles de encontrar entre el arte rupestre de Utah, y casi todos los otros lugares. Aunque son difíciles de encontrar, el papel de género y las mujeres todavía pudo haber sido importante a las culturas que produjeron el arte. Asimismo, no podemos estar seguros que las figuras antropomórficas no representaban ambos los varones y las mujeres. Símbolos tales como la cúpula (tal como se mostró en el condado de Utah sitio 42UT1746) podrían representar vulvas o vaginas, pero no hay manera de estar seguros.

Tal como lo describe Kelley Hays-Gilpin, estas imágenes son “ambiguas” y no pueden tener una interpretación absoluta a menos que el autor mismo se la dé (Hays-Gilpin, 2004a). Es difícil aun hacer una conjetura fundamentada sin tener una gran comprensión de la gente que produjo el arte. Sin embargo, sí sabemos que las sociedades cazadoras-recolectoras son responsables por la mayoría de la producción del arte rupestre en Norte América occidental (Whitley, 1998). Investigación adicional en más condados, además de una comparación cruzada con otros sitios fuera de Utah, pueden ser beneficiosas para aprender más sobre los sitios en Utah. 
Además de las similitudes de estilo, no había patrones en común dentro o entre condados. Si el arte rupestre sí contiene cualquier figura antropomórfica, la mayoría no contiene atributos de sexo/género. Por lo tanto, no podemos hacer una determinación positiva sin comprender la cultura que lo creó.

\section{Conclusiones y contribuciones del estudio}

Aunque algunos motivos del arte rupestre se pueden interpretar más fácilmente, la mayor parte requiere un conocimiento amplio de la cultura y el análisis etnográfico para llegar a una conclusión probable. Identificar el sexo y género dentro de motivos de arte rupestre puede ser difícil sin comprender la construcción cultural ya que a menudo tenemos inclinaciones y suposiciones culturales propias. Cierta investigación sobre características de género/sexo en el arte rupestre está presente, pero hay más que estudiar, particularmente se necesitan estudios etnográficos y métodos más precisos de datación con el arte.

El arte de una cultura no se puede ignorar ni tomar a la ligera; "el arte tiene que tomarse en serio, como resultado de una reflexión y un compromiso situados dentro de un medio ambiente particular" (Porr \& Bell, 2012). El arte rupestre nos puede decir tanto sobre la cosmología y estilo de vida de una cultura. Comprender cómo se representa el género en el arte rupestre puede iluminar cómo funcionaban las relaciones de género dentro de una sociedad prehistórica. Lo que quiere decir esta lezna: arqueología feminista en una aldea wahpeton dakota de Janet D. Spector (1993) e Imágenes ambiguas de Kelley Hays-Gilpin (2004a) son fundamentales para comprender cómo inclinaciones de género se arraigan en la arqueología y cómo podemos estudiar el género en el arte rupestre. Este estudio puede ayudar a "desgenerizar" la arqueología y cómo estudiamos el arte rupestre. Sin embargo, nunca podemos estar seguros de que el arte rupestre represente características de género/sexo.

\section{Nota del traductor}

Todas las traducciones de citas y nombres de libros en el texto fueron realizadas por el traductor pero se dejan como originales en las referencias. 


\section{REFERENCES}

Bader, L. (2014). Third Genders: New Concept? Or Old? | The Evolution of Human Sexuality. Psu.Edu. https://sites.psu.edu/evolutionofhumansexuality/2014/02/19/third-genders-newconcept-or-old/

Barger, M. (1978). Antiquities Site Inventory: 42BO386. Utah Department of Heritage and Arts.

Bass, P. M. (1994). Chapter 6: A Gendered Search Through Some West Texas Rock Art. In D. S. Whitley \& L. L. Loendorf (Eds.), New Light on Old Art: Recent Advances in Hunter-Gatherer Rock Art Research (pp. 67-74). Cotsen Institute of Archaeology Press.

Bednarik, R. (2015). The First Stirrings of Creation. Academia. https://www.academia.edu/ 11300516/The first_stirrings_of creation

Birthing Scene. (2000). Climb-Utah.Com. https://www.climb-utah.com/Moab/birth.htm

Bowen, N., \& Manning, S. J. (2003). Utah Rock Art. Twenty-First Annual Symposium of the Utah Rock Art Research Association (URARA).

Brady, L. M. (2016). Contemporary Indigenous Relationships to Archaeological Features: Agency, Affect, and the Social Significance of Rock Art. Heritage E'Society, 9(1), 3-24. https://doi.org/ $\underline{10.1080 / 2159032 \times .2016 .1246153}$

Cartwright, C. (1979a). Antiquities Site Inventory: 42TO160. Utah Department of Heritage and Arts.

Cartwright, C. (1979b). Antiquities Site Inventory: 42TO209. Utah Department of Heritage and Arts.

Cole, S. J. (2009). Legacy on Stone: Rock Art of the Colorado Plateau and Four Corners Region. Johnson Books.

Frink, L., Shepard, R. S., \& Reinhardt, G. A. (Eds.). (2002). Many Faces of Gender: Roles and Relationships through Time in Indigenous Northern Communities. University Press of Colorado. https://doi.org/10.2307/j.ctv6cfrqv

Garrison, L. T. (2017). 6 Modern Societies Where Women Rule. Mental Floss. http://mentalfloss.com/article/31274/6-modern-societies-where-women-literally-rule

Geib, P. R., \& Fairley, H. C. (1992). Radiocarbon Dating of Fremont Anthropomorphic Rock Art in Glen Canyon, South-Central Utah.Journal of Field Archaeology, 19(2), 155. https://doi.org/ $\underline{10.2307 / 529976}$

Gero, J. M., \& Conkey, M. W. (2002). Engendering Archaeology: Women and Prehistory. WileyBlackwell.

Handsman, R. G. (2002). Whose Art Was Found at Lepenski Vir? Gender Relations and Power in Archaeology. In Engendering Archaeology: Women and Prehistory (pp. 329-365). Wiley-Blackwell.

Hays-Gilpin, K. (2004a). Chapter 6: Gender and Prehistoric Rock Art. In S. M. Nelson (Ed.), Ambiguous Images: Gender and Rock Art (pp. 122-141). Altamira Press.

Hays-Gilpin, K. (2004b). Chapter 12: Engendering Rock Art. In S. M. Nelson (Ed.), Ambiguous Images: Gender and Rock Art (pp. 199-213). Altamira Press.

Healy, M. (1999). IMACS Site Form: 42UT1586. Utah Department of Heritage and Arts.

Hedges, R. E. M., Housley, R. A., Law, I. A., \& Perry, C. (1987). Radiocarbon Dates from the Oxford AMS System: Archaeometry Date List 6. Archaeometry, 29(1), 289-306. https://doi.org/10.1111/ j.1475-4754.1988.tb00443.x

KBO. (1974). Survey Site Sheet: 42JB126. Utah Department of Heritage and Arts.

Keyser, J. D. (2001). Relative Dating Methods. In D. S. Whitley (Ed.), Handbook of Rock Art Research (pp. 116-138). Altamira Press. 
Liritzis, I. (2010). Strofilas (Andros Island, Greece): New Evidence for the Cycladic Final Neolithic Period through Novel Dating Methods Using Luminescence and Obsidian Hydration. Journal of Archaeological Science, 37(6), 1367-1377. https://doi.org/10.1016/j.jas.2009.12.041

Lødøen, T. (2003). Late Mesolithic Rock Art and Expressions of Ideology. In H. Kingdom, K. Knuttson, L. Larsson, \& D. Leoffler (Eds.), Mesolithic on the Move: Papers Presented at the Sixth International Conference on the Mesolithic in Europe, Stockholm 2000.

Manning, S. J. (2011). IMACS Site Form: 42UT1784. Utah Department of Heritage and Arts.

McMurtrey, K. (2015). Patterns in Rock Art: An Analysis of the Fremont Rock Art at the Smith Preserve.

Miller, B. (1996). IMACS Site Form: 42CB1045. Utah Department of Heritage and Arts.

Mullen, L. (2011). Reverence for the Heavens: How Astronomy and Religion Intersect. Space.Com. https://www.space.com/10656-astronomy-religion-cosmos-intersection.html

Namono, C. (2012). Dumbbells and Circles: Symbolism of Pygmy Rock Art of Uganda. Journal of Social Archaeology, 12(3), 404-425. https://doi.org/10.1177/1469605312455761

Namono, C., \& Eastwood, E. B. (2005). Art, Authorship and Female Issues in a Northern Sotho Rock Painting Site. Goodwin Series, 9(1), 77-85. https://doi.org/10.2307/3858036

Neculaesei, A. (2015). Culture and Gender Role Differences. Cross Cultural Management Journal, 1(1), 31-35. https://econpapers.repec.org/RePEc:cmj:journl:y:2015:i:7:p:31-35

Porr, M., \& Bell, H. R. (2012). 'Rock-art', 'Animism' and Two-way Thinking: Towards a Complementary Epistemology in the Understanding of Material Culture and 'Rock-art' of Hunting and Gathering People. Journal of Archaeological Method and Theory, 19(1), 161-205. https://doi.org/10.1007/s10816-011-9105-4

Rogers, R. A. (2007). From Hunting Magic to Shamanism: Interpretations of Native American Rock Art and the Contemporary Crisis in Masculinity. Women's Studies in Communication, 30(1), 78-110. https://doi.org/10.1080/07491409.2007.10162506

Rosenfeld, A., \& Smith, M. (2002). Rock-Art and the History of Puritjarra Rock Shelter, Cleland Hills, Central Australia. Proceedings of the Prehistoric Society, 68(1), 103-124. https://doi.org/ $\underline{10.1017 / s 0079497 \times 00001407}$

Rowe, M. W. (2001). Dating by AMS Radiocarbon Analysis. In D. S. Whitley (Ed.), Handbook of Rock Art Research (pp. 139-166). Altamira Press.

Sabo, G., \& Sabo, D. (2019). What Is Rock Art and What Can It Tell Us about the Past? Uark.Edu. http://archeology.uark.edu/rockart/ index.html?pageName=What $\% 20$ is\%20Rock\%20Art\%20and\%20What \%20 Can\%20it\%20Tell\%20Us\%20About\%20the

Sauvet, G. (2015). In Search of Lost Time. Dating Methods for Prehistoric Art: The Example of Aurignacian Sites. Palethnologie, 1(7). https://doi.org/10.4000/palethnologie.823

Schaafsma, P. (1971). The Rock Art of Utah: A Study from the Donald Scott Collection. University of Utah Press.

Scotter, T., \& Bowen, N. (2019). The Rock Art of Utah. Utah Rock Art Research Association (URARA). https://urara.wildapricot.org/page-18203

Shipley, S. C. (2019). Site Form: 42UT1746. Utah Department of Heritage and Arts.

Solomon, A. (1997). The Myth of Ritual Origins? Ethnography, Mythology and Interpretation of San Rock Art. The South African Archaeological Bulletin, 52(165), 3. https://doi.org/10.2307/3888971

Spangler, J. (2007). IMACS Site Form: 42CB958. Utah Department of Heritage and Arts.

Spector, J. D. (1993). What This Awl Means: Feminist Archaeology at a Wahpeton Dakota Village. Minnesota Historical Society Press.

Stuart, M. E. (1982). Site Survey Sheet: 42BO400. Utah Department of Heritage and Arts. 
Stuart, M. E. (1985). IMACS Site Form: 42BO2114. Utah Department of Heritage and Arts.

Stuart, M. E. (1986). IMACS Site Form: 42BO582. Utah Department of Heritage and Arts.

Stuart, M. E. (2007a). IMACS Site Form: 42BO1703. Utah Department of Heritage and Arts.

Stuart, M. E. (2007b). IMACS Site Form: 42BO1707. Utah Department of Heritage and Arts.

Whitley, D. S. (1998). Finding Rain in the Desert: Landscape, Gender and Far Western North American Rock-Art. In The Archaeology of Rock-Art (pp. 11-27). Cambridge University Press.

WorldAtlas, \& Sawe, B. E. (2019). Matriarchal Societies around the World. WorldAtlas. https://www.worldatlas.com/articles/matriarchal-societies-around-the-world.html

Wright, A. M., \& Russell, W. G. (2011). The Pipette, the Tiered Cosmos, and the Materialization of Transcendence in the Rock Art of the North American Southwest. Journal of Social Archaeology, 11(3), 361-386. https://doi.org/10.1177/1469605311403864

Wylie, A. (2002). Gender Theory and the Archaeological Record. In Why Is There No Gender of Archaeology? Engendering Archaeology: Women and Prehistory (pp. 31-56). Blackwell. 